\author{
PABLO CAMUS* \\ SERGIO CASTRO** \\ FABIÁN JAKSIC ${ }^{* * *}$
}

\title{
EL CONEJO EUROPEO EN CHILE: HISTORIA DE UNA INVASIÓN BIOLÓGICA
}

\begin{abstract}
Este trabajo analiza las relaciones entre los seres humanos y su ambiente, a partir de la historia de la aclimatación y posterior invasión de conejos en Chile, constatando que, en el largo plazo, las acciones humanas tienen efectos e impactos insospechados sobre el medio natural. En efecto, si bien inicialmente los conejos fueron vistos como una oportunidad de desarrollo económico a partir del aprovechamiento de su piel y su carne, pronto esta especie se convirtió en una plaga difícil de controlar en diversas regiones del país, como Chile central, Tierra del Fuego e islas Juan Fernández. Así, con el paso del tiempo, el conejo se ha terminado por transformar en nuestro país en un verdadero "convidado de piedra".
\end{abstract}

Palabras clave: Historia ambiental, invasiones biológicas, conejo europeo, ecología y medio ambiente.

This work analyses the relationship between human beings and their environment taking into consideration the adjustment and eventual invasion of rabbits in Chile. It argues that in the long run, human actions have unsuspected effects upon the environment. In fact rabbits were seen initially as an opportunity for economic development because of the exploitation of their meat and skin. Later, rabbits became a plague in different areas of Central Chile, Tierra del Fuego and Juan Fernández islands, which was difficult to control. Over the years rabbits became unwelcome guests in Chile.

Key words: Environmental History, biological invasions, European rabbit, ecology and environment.

Fecha de recepción: octubre 2007

Fecha de aceptación: abril 2008

* Centro de Estudios Avanzados en Ecología y Biodiversidad (CASEB). Correo electrónico: pcamusg@uc.cl

** Departamento de Biología, Facultad de Química y Biología; Universidad de Santiago de Chile. Centro de Estudios Avanzados en Ecología y Biodiversidad (CASEB). Correo electrónico: scastro@usach.cl

*** Departamento de Ecología, Pontificia Universidad Católica de Chile. Centro de Estudios Avanzados en Ecología y Biodiversidad (CASEB).Correo electrónico: fjaksic@bio.puc.cl 


\section{INTRODUCCIÓN ${ }^{1}$}

El proceso de globalización ha concitado modificaciones no solo en los patrones culturales y económicos del planeta, sino que también sobre el patrimonio biológico de los países involucrados ${ }^{2}$. Así, el aumento de la conectividad comercial y del transporte entre regiones remotas del planeta ha propiciado un intercambio de flora, fauna y microorganismos sin precedentes en la historia geológica ${ }^{3}$. En muchas ocasiones, la introducción de especies se realiza de manera intencional, como es el caso de aquellas con importancia económica y productiva. Sin embargo, en otras situaciones, la introducción es involuntaria y en muchos casos indeseada, como ocurre con especies de maleza o plaga.

Las especies invasoras han despertado un renovado y creciente interés en nuestra sociedad ${ }^{4}$. Por una parte, se ha reconocido que su presencia afecta el patrimonio natural (biológico) de las unidades geopolíticas recipientes, debido a que puede alterar la representación de especies nativas, y en algunos casos causar su extinción. Por otra, las especies invasoras afectan negativamente a los sectores productivos, debido a que pueden comportarse como malezas o plagas de cultivos. Finalmente, la llegada de nuevas especies puede implicar efectos en la salud humana, al introducir conjuntamente patógenos o sustancias deletéreas.

Aunque la dimensión biológica de estas invasiones comienza a ser mejor comprendida desde el punto de vista de la teoría ecológica, un aspecto claramente menos estudiado lo constituye su dimensión humana ${ }^{5}$. Esto es particularmente cierto si se considera que la conectividad global (i.e. globalización) está sustentada por relaciones entre unidades geopolíticas concretas (i.e. países), y que estas se han modificado profundamente en los últimos 500 años. Así, el estudio de la dimensión humana de las invasiones biológicas constituye una vertiente que permite comprender cómo se ha amparado, histórica, social y políticamente, la introducción de especies, y qué lecciones es posible extraer de estas experiencias para aplicarlas en el futuro, pues es probable que nuevos eventos de este tipo vuelvan a ocurrir.

En Chile continental, la introducción de especies invasoras comenzó tempranamente. El intercambio comercial entre las etnias originarias probablemente contribuyó a la expansión de numerosas especies y cultivos (quínoa, pimiento, camélidos, etc.). Sin embargo, es la colonización española la que impuso un cambio

1 Agradecemos la ayuda de Rodrigo Torres en la recopilación de antecedentes para la elaboración de este trabajo.

2 Peter M. Vitousek, Carla M. D’Antonio, Lloyd L. Loope y Randy Westbrooks, “Biological invasions as global environmental change”, en American Scientist, Vol. 84, N 5, Washington, 1996.

3 Richard N. Mack, Daniel Simberloff, Mark Lonsdale, Harry Evans, Michael Clout y Fakhri A. Bazzaz, "Biotic invasions: causes, epidemiology, global consequences, and control", en Ecological Applications, Vol. 10, $\mathrm{N}^{\mathrm{o}}$ 3, Washington, 2000.

4 D. Pimentel, L. Lach, R. Zuniga y D. Morrison, Environmental and economic costs associated with non-indigenous species in the United States, Ithaca, NY, College of Agriculture and Life Sciences, Cornell University, 1999.

5 J.A. McNeely, The great reshuffling: how alien species help feed the global economy, Gland, Suiza, IUCN, 2001. 
cualitativo y cuantitativo a esta dinámica, pues se introducen especies provenientes de un continente lejano, cuyos vínculos evolutivos y biogeográficos con la biota local son remotos ${ }^{6}$. Con la instauración de la República se estimuló activamente la apertura comercial y el desarrollo ganadero y silvo-agropecuario interno, lo que posibilitó la introducción de nuevas crianzas y cultivos. Como resultado, Chile cuenta con 24 especies de vertebrados y 800 especies de plantas invasoras, la historia de su introducción, en su contexto social y biológico, permanece, en su mayor parte, desconocida.

El conejo europeo (Oryctolagus cuniculus L.) ocupa un lugar importante entre la fauna invasora de Chile ${ }^{7}$. Siendo una especie introducida -aparentemente con propósitos comerciales-, la crianza en conejeras en Chile central llevó a su escape o liberación en ambientes naturales. Alcanzado el estatus de especie silvestre, esta especie no solo logró expandir su distribución geográfica, sino que alcanzó abundancias poblacionales considerables, al punto de causar perjuicios económicos al sector silvo-agropecuario y convertirse, de paso, en una especie plaga: un convidado de piedra ${ }^{8}$. En la actualidad, la presencia del conejo europeo en Chile no solo se observa en la porción central del territorio, sino también en el archipiélago de Juan Fernández, Tierra del Fuego y parte de la Patagonia chileno-argentina.

En este artículo revisamos y analizamos los antecedentes históricos disponibles que acreditan la introducción de conejos en Chile. Específicamente, intentamos cubrir dos aspectos de esta problemática: por una parte, reconstruir la historia de esta invasión, focalizándonos en la evidencia documental disponible; y por otra, analizar el contexto político y social que desencadenó la introducción y asilvestramiento de una de las especies más preocupantes para el sector forestal y agrícola chileno. Con estos antecedentes, intentaremos extraer algunas lecciones relevantes acerca de la introducción de especies en Chile y la necesidad de un diálogo virtuoso entre la investigación científica y la toma de decisiones políticas, las que han acompañado y acompañarán la conexión multilateral de nuestro país de cara a la globalización.

\section{EL CONEJO EUROPEO}

El conejo europeo es una especie nativa de la Península Ibérica. Originalmente su distribución estuvo restringida por los eventos de glaciación que afectaron al continente europeo, determinando la aparición de dos subespecies: O. cuniculus

6 Sergio A. Castro, Javier A. Figueroa, Mélica Muñoz-Schick y F.M. Jaksic, "Minimum residence time, biogeographical origin, and life cycle as determinants of the geographical extent of naturalized plants in continental Chile", en Diversity \& Distributions, Vol. 11, N ${ }^{\circ} 3$, Stellenbosch, South Africa, 2005.

7 Fabián M. Jaksic, "Vertebrate invaders and their ecological impacts in Chile", en Biodiversity \& Conservation, Vol. 7, N 11, Springer, Netherlands, 1998.

8 Fabián M. Jaksic y Eduardo Fuentes, “El conejo español: ¿un convidado de piedra?”, en E. Fuentes y S. Prenafeta (eds.), Ecología del paisaje en Chile central: estudios sobre sus espacios montañosos, Santiago, Ediciones Universidad Católica, 1988. 
cuniculus y O. cuniculus algirus ${ }^{9}$. La primera subespecie se distribuye en la porción noreste de la península y en el sudeste de Francia, mientras que la segunda se halla al suroeste de España, incluyendo Portugal. La gran fecundidad exhibida por esta especie, así como su importancia peletera y comestible, probablemente motivaron su introducción en diversas regiones del mundo (i.e. Asia, África, Australia, Nueva Zelanda y América), incluyendo numerosas islas oceánicas. Así, en este último caso, la dotación de conejos proveería de sustento alimenticio a los primeros viajeros interoceánicos de los siglos XV y XVI en adelante. En muchas de estas localidades el conejo terminó asilvestrándose y transformándose en una especie indeseada. Este es el caso de Australia, donde no hubo conejos hasta que el velero Lightning llevó, en 1859, dos docenas de ellos encargados por el terrateniente Thomas Austin, quien no se quería privar de la tradicional caza del conejo. Los conejos liberados por Austin no tenían depredadores naturales, por lo que se multiplicaron con una rapidez abismante. En pocos años llegaron a convertirse en millones y progresivamente fueron ocupando el continente australiano sin que nada los detuviera. Como paliativo se importaron zorros desde Inglaterra, pero ellos prefirieron depredar la fauna marsupial indígena y casi terminaron por exterminarla. Posteriormente, se colocó una alambrada de 11.000 kilómetros a través de todo el país, sin resultados. En diez años Australia exportó 700 millones de pieles de conejos y 160 millones de conejos congelados. Todas las medidas para eliminar el conejo fueron inútiles, hasta que en 1950 los científicos comenzaron a inyectar el virus mixoma a los conejos. Los mosquitos se encargaron de transmitir la enfermedad, hasta que, para 1951, la propagación del mixoma había alcanzado su punto máximo ${ }^{10}$.

Prácticamente en todos los países en que se ha introducido el conejo, este ha sido un colonizador exitoso y ha demostrado su potencial destructor para los ecosistemas, los cultivos y el ganado. Por ello, el conejo ha llegado a ser uno de los ejemplos clásicos que se utilizan para caracterizar los impactos provocados por las invasiones biológicas. Al mismo tiempo, paradójicamente, en muchos países el conejo ha sido introducido deliberadamente con el objetivo de practicar la cacería, obtener carne y pieles, e inclusive para ser adoptado por familias como mascota. En Europa y otros continentes, el conejo ha sido por siglos objeto de altercados y rivalidades entre los "arrendatarios" y los "grandes propietarios", quienes se disputaban los derechos de propiedad sobre su caza, por lo que el estatus jurídico del conejo fue objeto de largas deliberaciones, querellas y legislaciones. En la segunda mitad del siglo XX, los programas de investigación científica, bajo el amparo de

9 Christophe Biju-Duval, Hajer Ennafaa, Nicole Dennebouy, Monique Monnerot, Françoise Mignotte, Ramon C. Soriguer, Amel El Gaaïed, Ali El Hili y Jean-Claude Mounolou, "Mitochondrial DNA evolution in lagomorphs: origin of systematic heteroplasmy and organization of diversity in European rabbits", en Journal of Molecular Evolution, Vol. 33, N 1, New York, 1991.

Monique Monnerot, Jean-Denis Vigne, Christophe Biju-Duval, Didier Casane, Cécile Callou, Florence Mougel, Ramon C. Soriguer, Nicole Dennebouy y Jean-Claude Mounolou, "Rabbit and man: genetic and historic approach", en Genetics Selection Evolution, No 26, Supl. 1, París, 1994.

10 J. Voigt, La destrucción de equilibrio biológico, Madrid, Alianza, 1987, 146-150. 
los gobiernos nacionales, han establecido costosos laboratorios de experimentación médica y programas de control de esta especie. En suma, el conejo es una especie económicamente importante, que se adapta eficaz y rápidamente, al mismo tiempo que un seguro y exitoso colonizador ${ }^{11}$.

\section{ORÍGENES DEL CONEJO EN CHILE}

En 1892, Lataste indicó que los primeros ejemplares de O. cuniculus fueron ingresados a Chile en 1884. Esta introducción habría ocurrido en una isla que existía en el lago Cauquenes (en la actual VI Región), sitio desde el cual se habrían expandido a lo largo del territorio de Chile central. A pesar de que la versión de Lataste fue ampliamente aceptada, el reciente examen de la evidencia histórica disponible sugiere otra interpretación. En efecto, después de investigar en las primeras crónicas y otras fuentes, tales como las actas del Cabildo, los relatos de viajeros y las impresiones de distintos actores que describen los elementos del medio natural en Chile, podemos señalar que el primero en señalar la presencia de conejos en el país fue Juan Ignacio Molina, más de un siglo antes de lo planteado por Lataste. De esta manera, los registros históricos indican que hubo conejos en Chile desde antes de lo convencionalmente aceptado en la literatura. En todo caso, subsisten preguntas que la documentación consultada no resuelve. Por ejemplo, ¿en qué momento fueron introducidos? y ¿en qué momento se naturalizaron?

Como se señaló, las primeras referencias a la presencia de conejos en Chile, aunque en forma indirecta, fueron escritas por el jesuita Juan Ignacio Molina, quien al caracterizar al "cuy" señalaba que, a pesar de toda la semejanza que tiene con los conejos, "huye de su compañía y jamás se han visto asociados ni juntos estos animales"12. En su Ensayo sobre la historia natural de Chile, Molina planteaba que tanto el cuy como el conejo "temen mucho a los gatos y topos, que son sus enemigos y depredadores"13. Al mismo tiempo, refiriéndose a las vizcachas, Molina señalaba que "aquellas gentes [los campesinos] prefieren la carne de este animal, que es blanca y mui tierna, a la de los conejos y de las liebres"14. Considerando que Molina fue expulsado en 1768, a la edad de 28 años, estas observaciones indican que hacia mediados del siglo XVIII los conejos ya habían sido introducidos en Chile, pues el autor los menciona para comparar sus hábitos en el contexto nacional y para clarificar y significar sus descripciones de cuys y vizcachas al medio europeo, al cual dirige su obra sobre la historia natural de Chile.

11 H. Thompson y C. King (eds), The European Rabitt. The history and biology of a sucessful colonizer, Oxford, Oxford Science Publications, 2004.

12 Juan Ignacio Molina, Compendio de la historia civil del Reyno de Chile, Madrid, Imprenta de Sancha, 1788-1795, tomo I, LXXXVIII, 348.

13 Juan Ignacio Molina, Ensayo sobre la historia natural de Chile, Santiago, Ediciones Maule, $1987,288$.

14 Molina, Compendio..., op. cit., tomo I, LXXXVIII, 289. 
No obstante, al menos hasta mediados del siglo XIX, los conejos no eran considerados en Chile como una especie invasora o problema. Así lo estimaba Claudio Gay, quien señaló que esta especie era "desgraciadamente poco abundante con relación a los numerosos servicios que presta su carne como alimento y sus pelos como fieltro para los sombreros"15. En su tratado de Zoología, Claudio Gay indicaba que el conejo que había en Chile era "de un gris mezclado de flavo en el estado salvaje, con bermejo en la nuca; su garganta y vientre son blanquizos. Las orejas casi de la longitud de la cabeza. La cola menos larga que el muslo y bruna por cima; pero en el estado doméstico los colores varían mucho". Lo cual nos indica que, en su percepción, antes de mediados del siglo XIX, había conejos silvestres o salvajes en Chile, aunque no en la abundancia requerida, para un francés acostumbrado a ellos, para ser percibidos como plaga. En consecuencia, Gay señalaba que en Chile "sería sin duda útil que se tratase de propagarlos en el estado salvaje, sobre todo en las grandes comarcas próximas á las cordilleras donde los terrenos no están todavía cultivados, pues ofrecerían además de una carne mucho más gustosa y sana que la de los caseros, gran cantidad de pieles, que el arte de la sombrerería emplea tan generalmente y con tanta ventaja"16.

Tenemos, en todo caso, más noticias de la existencia de conejos a mediados del siglo XIX y también de los primeros indicios de su potencial como plaga ambiental, a partir de referencias de las que disponemos sobre un conejar establecido antes de 1849. Así lo recuerda Nathan Miers, quien señala que ese año Manuel Ruiz Tagle le había contado que "en su fundo La Calera tenía una conejera de cómo cuatro cuadras de extensión, con muchos conejos. Averiguando sobre ella, colijo que, muerto él, sus herederos no cuidaron los conejos, i es probable, según la explicación que se me ha hecho, que, encerrados con paredes de cal y ladrillo y no recibiendo alimentación, perecieron en su mayor parte. Algunos deben haber escapado. Porque hace pocos días, alguien me contó que en territorios vecinos de la Calera se ven conejos" 17 .

En suma, de los planteamientos de Juan Ignacio Molina, Claudio Gay y Nathan Miers se puede deducir que, a diferencia de lo planteado originalmente por Fernand Lataste, había conejos en Chile con anterioridad a 1884. Aunque probablemente estos fueron mantenidos bajo cautiverio, en atención a su carne y piel, no está claro si las poblaciones de conejos asilvestrados en el territorio central de Chile fueron conformadas por individuos liberados o escapados de la crianza. Por otra parte, con la evidencia disponible no es posible determinar si la introducción de conejos al país se realizó en una o varias oportunidades, o si sus escapes o eventos de liberación ocurrieron en más de una ocasión. Lo concreto es que, para fines del siglo XIX, ya existía la crianza cautiva de conejos, así como conejos asilvestrados en Chile central.

15 Claudio Gay, Agricultura Chilena, Santiago, ICIRA, 1973, 477.

16 Claudio Gay, Historia física y política de Chile. Zoología, tomo I, Santiago, Museo de Historia Natural de Santiago, 1847, 126.

17 Nathan Miers, "Invasión de los conejos", en Boletín de la Sociedad Nacional de Agricultura, Vol. XXI, No 22, Santiago, 28 de mayo de 1900, 453 y 454. 


\section{AClimatación Del CONEJO EN CHILE}

Hacia el último tercio del siglo XIX se inició una interesante polémica acerca de la aclimatación del conejo en Chile y de los beneficios que la crianza de esta especie podía tener en el desarrollo económico nacional, especialmente para los sectores más desprovistos de recursos. Para unos se trataba de una especie muy rentable, que, por su capacidad para multiplicarse rápidamente, proporcionaría en abundancia y a bajo costo pieles y carne para el consumo de las familias del campo; mientras que para otros, como Rodulfo A. Philippi, se trataba de una especie que, si escapaba de sus planteles, podía causar enormes estragos a la agricultura, tal como había ocurrido en otras regiones del mundo. En todo caso, la mayoría de los autores advertía sobre la importancia de cerrar muy bien las conejeras, para que estos animales no pudiesen alcanzar la libertad.

Es así como en 1870 el Boletín de la Sociedad Nacional de Agricultura publicó un artículo titulado "Cría del Conejo", en el que destacaba la importancia del conejo en los campos, señalando que, hasta entonces, este vertebrado desempeñaba "un papel secundario en nuestros corrales", pero que en otras latitudes era reconocido por "su carne blanca, limpia y de un gusto siempre agradable, no empalaga y se puede guisar mil diversas maneras. Pero no es lo exquisito de su gusto lo que nos hace realzarlo en este ligero estudio que le dedicamos; es una consideración superior todavía y que se roza con la economía doméstica del pobre: es la importancia que tiene como alimento para las familias campestres". En consecuencia, el artículo concluía "recomendando a nuestros hacendados su difusión entre los campesinos". En todo caso planteaba que la conejera debía ser "construida con un material que impida la salida del conejo, que es diestro y esforzado en hacer grandes cuevas donde se oculta al principio y por donde se proporciona la libertad al fin"18.

Santos Tornero también alentaba, en aquel período, el desarrollo de la presencia de los conejos en Chile. En 1875, destacaba los beneficios de crianza de esta especie, al señalar que era útil, "cuando en condiciones apropiadas se multiplica la raza doméstica. Su asistencia es poco costosa, y además de los productos, da una excelente carne, su piel y su pelo tienen mucho valor, y como se presta a que las familias pobres los críen, son un gran recurso para la economía doméstica"19. Sin embargo, al mismo tiempo, advertía sobre lo "dañino del conejo en estado de libertad" 20 .

Ese mismo año, el Boletín de la Sociedad Nacional de Agricultura publicó nuevamente un artículo sobre la cría del conejo "para manifestar la gran utilidad que en otros países sacan los agricultores de este ramo mui descuidado de la República", en el cual se señalaba que "en cuanto a las conejeras al aire libre es

\footnotetext{
18 "Cría del conejo", en Boletín de la Sociedad Nacional de Agricultura, Vol. I, No 1, Santiago,

19 Santos Tornero, De la cría y propagación de animales domésticos, Valparaíso, Librería del Mercurio, 1875, 175.

20 Idem.
} 1870,168 . 
preciso tener presente que cuanto mayor sea la extensión tanto mejor prosperarán. Cada conejera debe ser cerrada exactamente por todas partes, con tapias de cal y canto de unos diez pies de altura i con los cimientos bastante profundos para que los conejos no puedan pasar por abajo [...] Ojalá que uno de nuestros compatriotas que actualmente se hayan en Europa pasase a Flandes para adquirir algunos pares de estos animales bonitos y provechosos" ${ }^{21}$. Texto que se puede interpretar como una preocupación por la posible invasión de conejos, dada su ya conocida fecundidad, o como una inquietud por la pérdida de productividad del conejar a partir de la salida de algunos ejemplares.

Diez años más tarde, el naturalista Rodulfo Amando Philippi pensaba que, de acuerdo a sus observaciones, "los conejos no se han hecho salvajes por felicidad, a pesar que algunos franceses hayan tratado de ponerlos en una que otra chacra para tener el gusto de cazarlos i de comer su carne, mui estimada en Francia. Pronto se ha visto el gran daño que hacían i se han exterminado antes de que hayan podido volverse salvajes. Los ingleses, grandes cazadores de conejos, los han transportado a Australia, donde se han multiplicado en algunos puntos de un modo tan excesivo que llega a ser una plaga; de modo que los pobladores no saben como librarse de estos animales, que amenazan con devastar toda plantación"22. Es interesante analizar este comentario de Rodulfo Philippi, pues es la primera referencia que tenemos acerca de la plaga de conejos en Australia, tópico que será más que recurrente para explicar los perjuicios del conejo en la documentación disponible en las décadas siguientes. Por otra parte, señala algunas acciones emprendidas para exterminarlos antes de que se volviesen salvajes, y, especulando, pensamos que de algún modo cuestiona los planteamientos del francés Claudio Gay, ya referidos, acerca de la conveniencia de soltar conejos a la vida silvestre.

Por su parte, René Le Feuvre, director de la Quinta Normal de Agricultura, planteaba que la crianza de conejos convenía "sobre todo a los pobres del campo; tanto porque les permite variar algo su alimentación, como porque puede efectuarse muy económicamente haciendo recoger por niños, ordinariamente muy desocupados, las yerbas y malezas de que se alimentan estos animales" 23 . Consecuente con las lecciones de Le Feuvre, director del más importante centro de experimentación agrícola del país, en 1900 la Escuela Práctica de Agricultura de Chillán informaba que en su establecimiento los conejos "se han multiplicado bastante hasta formar una buena base para explotarlos en mayor escala"24.

En cambio, Nathan Miers, un colaborador frecuente del Boletín de la Sociedad Nacional de Agricultura, temía los efectos de la propagación de los conejos en Chile, debido a su asombrosa fertilidad. Así, discutiendo las visiones que ensalzaban las bondades económicas del conejo, señalaba que:

21 "Cría del conejo", en Boletín de la Sociedad Nacional de Agricultura, Vol. VI, N 13, Santiago, 1875,346 .

22 Rodulfo Philippi, "Sobre los animales introducidos en Chile desde su conquista por los españoles", en Anales de la Universidad de Chile, LXVIII, Santiago, junio de 1885, 323 y 324.

23 René Le Feuvre, Lecciones teórico-prácticas de Agricultura y Zootecnia: dadas a los alumnos de la Escuela Normal de Preceptores, Valparaíso, Imprenta Excelsior, 1885, 345.

24 Memoria del Ministerio de Industria y Obras Públicas, Santiago, 1900, 18. 
"El año pasado hice los siguientes apuntes relativos a un par de conejos que tenia: el macho era blanco i la hembra negra. Esta parió ocho chicos el 26 de Octubre; siete el 27 de Noviembre siguiente, i nueve el 2 de Enero. Así, en 68 días un par se multiplicó hasta 27. Calculando que el primer par procreara durante siete meses del año; i que sus hijos solo desde seis meses de edad, se puede establecer que en un año podría contarse con 570. Este cálculo no es fantástico, es sí algo todavía mui limitado, cuando se considera que el estado natural de plena libertad i suficiente alimento es siempre mas favorable para la procreación que el artificial i de confinamiento" 25 .

Posteriormente, en 1900, Miers volvió a advertir en el Boletín de la Sociedad Nacional de Agricultura sobre "la asombrosa fecundidad del conejo". Señalaba en esta oportunidad que este hecho debería ser conocido, pues se hallaba destacado en todos los "trataditos" sobre cunicultura utilizados, además de citar el caso de Nueva Gales del Sur en Australia, sobre el cual escribía “cualquiera puede medir la extensión de lo que puede alcanzar a ser la invasión de los conejos con los datos que suministra el señor F. A. Coghlan, estadístico de gobierno en su obra sobre $L a$ riqueza y el progreso de Nueva Gales del Sur" ${ }^{26}$. Así, Miers señalaba que los argumentos expuestos eran suficientes, a su juicio, para "saber a que atenerse largando los conejos al campo"27.

También advirtiendo sobre los peligros de la propagación del conejo, en 1912 Luis Castillo escribió que

"en Chile, especialmente en la región central, que comparte sus caracteres con la región de origen, este roedor ha encontrado un suelo apto para socavar y abundancia de cercas vivas para protegerse de la persecución de que es objeto por los daños que causa. Se encuentra aquí tan bien, tan a su gusto que se multiplica prodigiosamente invadiendo los campos de cultivo con asombrosa rapidez, para lo cual cuenta con el valioso concurso de la zarzamora, planta invasora que le sirve de guarida inviolable, salvo por el fuego" 28 .

Asimismo, Castillo señalaba que

"el conejo como muchos otros seres orgánicos aclimatados fuera de su país de origen, ha encontrado en otras regiones de la tierra condiciones tan aptas para prosperar que han adquirido un grado de rusticidad completamente imprevisto por sus introductores. Es lo que ha pasado en Chile con el manzano y también con el pez dorado, la galega como yerba fanagerta i la zarzamora, tres calamidades. En Chile dichas plantas, como el pez dorado, han hallado en el clima, en la calidad del suelo y en la falta de todos aquellos agentes naturales que en un sentido u otro se oponen a su multiplicación y diseminación, condiciones tan favorables a su rusticidad que de seres útiles se han transformado en nocivos" 29 .

25 Boletín de la Sociedad Nacional de Agricultura, Vol. XXIV, N ${ }^{\circ}$ 15, Santiago, 5 de agosto de 1893,445 .

26 Miers, "Invasión de los conejos", op. cit., 453-454.

27 Idem.

28 Luis Castillo, "El conejo en libertad", en Boletín de bosques, pesca y caza, Vol. I, N ${ }^{\circ} 4$, Santiago, octubre de 1912, 253.

29 Ibid., 261. 
En otro artículo, Castillo planteaba que "el conejo y la zarzamora no solo han hallado en Chile fácil aclimatación sino también se han vuelto silvestres de modo imprevisto hasta el extremo de convertirse en seres altamente perjudiciales para la agricultura" 30 .

Al año siguiente, el Boletín de la Sociedad Nacional de Agricultura señalaba, en un artículo sobre plagas y problemas de la agricultura, que

"en los campos de la costa de las provincias de Santiago, Colchagua i en la de O'Higgins existe una gran cantidad de conejos silvestres, cuyo orijen no se conoce con exactitud, pues mientras algunos sostienen que fueron soltados de esprofeso para el sport de la caza, otros dicen provienen de conejos escapados de las jaulas en que se les mantenía. Ello es que la plaga ya ha pasado al sur del Maipo i alcanza hasta la laguna de Aculeo. Por ahora lo mejor que se hace es cazarlos de todas maneras i como son apreciados por su carne, cada día se les combatirá mas. Es conveniente destruir por el fuego las manchas de zarzamora que es donde más les agrada guarecerse. El medio mas práctico es el empleo de lazos especiales hechos con alambre delgado, los que se colocan en los puntos más traficados por los conejos, estos al pasar introducen la cabeza en el lazo y se ahorcan. De esta manera se cazan cada día grandes cantidades" 31 .

A pesar del peligro del conejo como especie invasora, los beneficios económicos que se esperaba obtener a partir de la explotación de su piel y de su carne permitieron considerar a esta especie como una oportunidad para el desarrollo del país, sobre todo para los pequeños propietarios agrícolas. En efecto, especialmente a partir de la década de 1920, comienza en la documentación disponible una persistente campaña para introducir la cunicultura como una buena alternativa de desarrollo económico. En 1921, por ejemplo, Carlos Echeverría publicó un manual de cunicultura en el que señalaba que

\begin{abstract}
"la industria del conejo es una de las pocas que podría fácilmente i en el corto tiempo convertirse en una verdadera fuente de riqueza para nuestro país y en los momentos actuales son los más apropiados para su desarrollo ya que no exige gran capital i que contribuiría poderosamente a resolver en muchos puntos el abastecimiento de carne para la alimentación ... las personas desocupadas o impedidas para hacer trabajos forzados, las mujeres que viven en los campos i poblaciones rurales pueden fácilmente cuidar dos o tres conejos de cría i proporcionarse un alimento mui nutritivo a menor precio".
\end{abstract}

\title{
En todo caso, Echeverría advertía que
}

"la mayoría de los conejos que se venden en nuestros mercados son los provenientes de los conejos que viven en libertad i que algunas personas han soltado para que se propa-

30 Luis Castillo, "Migraciones observadas en la fauna y flora de Chile", en Boletín de bosques, pesca y caza, Vol. II, No 4, Santiago, octubre de 1913, 251.

31 "Cartilla práctica sobre las enfermedades de árboles y cultivos, causadas por insectos y animales. Remedios", en Boletín de la Sociedad Nacional de Agricultura, Vol. XLV, N 9, Santiago, 15 de septiembre de 1914,528 . 
guen y poder después dedicarse a la caza sin imaginarse el gran perjuicio que ocasionan a nuestra agricultura, inutilizando las cosechas i minando los terrenos $\mathrm{i}$ aun las casas para construir sus madrigueras" 32 .

En marzo de 1928, la Sociedad Nacional de Agricultura publicó un artículo titulado "La cría del conejo", donde destacaba que "entre las pequeñas industrias agrícolas, una de las más lucrativas tal vez es la cría del conejo, tanto por su carne fina y delicada, como por su piel, que adquiere cada día mayor importancia comercial" 33 . Pocos meses después, en junio de 1928, el Boletín de la Sociedad publicó "Consejos para la producción de piel", donde se afirmaba que "la industria peletera ha alcanzado tal perfeccionamiento que transforma la piel de los prolíficos conejos en lujosos tapados de armiño, lutre, castor y otras imitaciones que por su elegancia y economía se han conquistado la adopción general en las modas femeninas". Por ello, se estimaba que "con razón el Ministerio comienza a preocuparse de dar vida a una explotación sumamente sencilla, propia de hogares modestos y capaz de rendir apreciables utilidades". Finalmente, enfatizaba que

"la piel de conejo ahora ya ha triunfado y no hay necesidad de disfrazarla bajo otros nombres para que se les otorgue la estimación que merece. Nuestras damas no tendrán por que considerar en menos las confecciones con esta clase de pieles, puesto que la moda más reciente, en los países que la imponen, está a su favor y los mismos personajes reales aceptan llevar pieles de este origen" 34 .

El Boletín de dicho mes destacó también "la exhibición de conejos hecha en las vitrinas de Gath y Chaves" y el folleto que se repartía allí sobre los beneficios posibles de la crianza de conejos para obtener su piel. Los editores del Boletín planteaban, asimismo, que estas iniciativas del Departamento de Tierras y Colonización, dependiente del Ministerio de Fomento, eran una prueba del interés por auspiciar el nacimiento de una lucrativa industria como la de pieles. En consecuencia, exclamaban: "Felicitémonos de que haya llegado la hora en que sea tomada en cuenta una riqueza del país a la cual no se había mirado en serio hasta ahora". No obstante, advertían que no bastaba con la "pequeña industria fácil de establecer en quintas o terrenos cercanos a las ciudades, sino que es menester ir a la industrialización de explotaciones hechas en grande escala, establecidas con ayuda del Estado, por lo menos en lo que se refiere a la entrega de ciertas porciones de territorio que se dedicaría exclusivamente a ese fin". Planteaban además que el Gobierno debía eliminar los derechos de aduana para los ejemplares vivos que se introdujesen al país y, tomando el ejemplo de Estados Unidos y Canadá, conceder “el arrendamiento de islas a lo largo del litoral chileno, donde las hay en gran canti-

32 Carlos Echeverría, Conejos y conejeras. Lecciones prácticas sobre los medios de manejar esta industria, 1921, 2-4.

33 "La cría del conejo", en Boletín de la Sociedad Nacional de Agricultura, Vol. LX, N ${ }^{\circ} 3$, Santiago, marzo de 1928, 172.

34 "Consejos para la producción de piel", en Boletín de la Sociedad Nacional de Agricultura, Vol. LX, No 6, Santiago, junio de 1928, 381 y 382. 
dad, completamente abandonadas, sin que reporten ninguna utilidad al fisco ni a la economía nacional y que ofrecerían espléndido campo para toda clase de crianzas con fines peleteros" 35 .

Al mes siguiente, julio de 1928, el jefe del Departamento de Tierras y Colonización dirigió "una nota al presidente de la Sociedad Nacional de Agricultura invitándolo a cooperar en la campaña que dicho departamento se ha propuesto emprender para intensificar la explotación de los animales de piel, principalmente en el ramo de la cunicultura". En la nota, la autoridad dejaba constancia de la buena calidad de las pieles chilenas que se exportan y de que, "a pesar de las condiciones deficientes en que se las prepara, son estimadas como de primera calidad en el extranjero". Además, añadía que "nuestras fábricas de sombreros tienen una demanda anual de pelo de conejo avaluada en dos millones de pesos, materia prima que hasta hoy día necesitan importar" 36 . Respondiendo a la solicitud del Departamento de Tierras y Colonización, el presidente de la Sociedad Nacional de Agricultura planteó que "su institución siempre había tratado de fomentar en nuestros campos todas estas pequeñas explotaciones e inspirada en tales propósitos no ha descuidado jamás el publicar en su boletín toda noticia útil sobre esta materia. Últimamente nuestra revista a creado una sección especial que trata de la cunicultura" 37 .

Efectivamente, a partir de entonces, se sucedieron una serie de publicaciones, tanto en el Boletín de la Sociedad Nacional de Agricultura como en folletos, documentos oficiales, artículos y libros, que planteaban la necesidad de implementar la cunicultura como una posibilidad de desarrollo de industrias agrícolas en pequeña escala. Por ejemplo, entre abril de 1928 y septiembre de 1929, el Boletín de la Sociedad Nacional de Agricultura publicó: "Preceptos de higiene y alimentación para conejos", "Conejos para producción de piel", "La explotación del conejo de angora", "La explotación lucrativa del conejo de angora", "La depilación del angora", "El conejo castorex", "Castorex robusto y rústico", "La coccidiosis en los conejos" y "La coriza en los conejos". En este mismo contexto, en la Revista de Ganadería y Agricultura Veterinaria, se publicó un artículo titulado "La cría de conejos y su reproducción", donde se señalaba que "es un hecho conocido que en Chile la crianza de conejos ha alcanzado en estos últimos tiempos bastante desarro$110 " 38$.

No es de extrañar, por lo tanto, que dada la reconocida fecundidad de los conejos, pronto surgieran nuevas preocupaciones, advertencias y también algunas medidas para controlar el crecimiento poblacional de estas especies en el país. En suma, en las últimas décadas del siglo XIX y primeras del XX, se inició un debate

35 "Medida indispensable que el Gobierno debe adoptar a favor de la industria peletera nacional", en Boletín de la Sociedad Nacional de Agricultura, Vol. LX, Nº 6, Santiago, junio de 1928, 385.

36 "Cunicultura. La explotación del conejo de Angora", Boletín de la Sociedad Nacional de Agricultura, Vol. LX, No 7, Santiago, julio de 1928, 457.

37 Idem.

38 "La cría de conejos y su reproducción", en Revista de Ganadería y Agricultura Veterinaria, Año V, N ${ }^{\circ} 53$, Santiago, 1930, 692. 
acerca de los beneficios o perjuicios de la aclimatación del conejo y el establecimiento de la cunicultura, especialmente como oportunidad de negocio para los pequeños propietarios agrícolas. El conejo era apreciado por su rápida multiplicación, la facilidad de su crianza y los beneficios que reportaba la explotación de su piel y de su carne. No obstante, muchos veían en el conejo un peligro, pues las posibilidades de que escaparan algunos y formaran colonias silvestres eran muy altas. De hecho, de ello dan cuenta los agentes promotores de la cunicultura, quienes hacen una diferencia entre los conejos silvestres y los conejos criados. Las primeras advertencias categóricas sobre los perjuicios del conejo las hacen Philippi, en 1885, Miers, en 1900, y Castillo, en 1912, quien ya advierte los primeros signos de una plaga de conejos en Chile central. Es así como, junto con el desarrollo de la cunicultura, promovida por agentes fiscales, como el Departamento de Tierras y Colonización, y organismos gremiales, como la Sociedad Nacional de Agricultura, a fines de la década de 1920 era cada vez más evidente la existencia de una plaga de conejos en Chile.

\section{CONEJOS EN CHILE CENTRAL}

Hacia fines de la década de 1920 los conejos se hallaban por todo el valle central. En 1929, por ejemplo, Camacho reconocía como

"un hecho innegable que en algunas partes del país tenemos establecida la plaga del conejo, que causa perjuicios importantes en las plantaciones, sembrados y praderas. [...] Esta plaga según informaciones que tengo sigue extendiéndose y puede que en fecha no lejana, sea necesario tomar medidas para evitar que continúe aumentando la superficie invadida y para controlar la situación en las partes ya invadidas" ${ }^{39}$.

Por otra parte, en la discusión parlamentaria de la Ley de Caza de 1929, se incluyó un artículo que permitía al Presidente de la República autorizar la caza de animales perjudiciales o dañinos sin la cédula a que se refería el artículo $2^{\circ}$, en cualquier tiempo, aun en los períodos de veda. Asimismo, reconociendo el carácter de plaga que estaba adquiriendo por aquellos años el conejo en Chile, en la Cámara de Diputados, el honorable García Henríquez señalaba que el proyecto gravaba "la caza del conejo, cuando en otros países se paga por que los maten”. Lo alarmante era que "La Nación y El Mercurio, editorialmente, han pedido que se de una batida a los conejos que constituyen una plaga. Sin embargo aquí se va a cobrar a los que los matan" 40 . Por su parte, el senador Yrarrázaval planteaba la necesidad de fomentar la caza del conejo, no solo reduciendo los impuestos por derecho de exportación propuestos por el proyecto, sino que "en cambio establecería una disposi-

39 C. Camacho, "El conejo Silvestre", en Boletín del Departamento de Agricultura, Año I, N 10/ 12, Santiago, octubre/diciembre de 1929, 3 .

40 Chile. Congreso Nacional, Cámara de Diputados, Diario de Sesiones. Publicación Oficial de la Cámara de Diputados, $41^{\mathrm{a}}$ sesión ordinaria en 10 de septiembre de $1928,1.246$. 
ción según la cual se pague una prima por la exportación del cuero de conejo debido a que este animal se ha extendido considerablemente hasta el extremo de ser una plaga en los campos agrícolas, como sucede en la región de Melipilla"41.

En 1930, Ismael Vicuña, cónsul de Chile en Bremen, envió una nota al Ministerio de Relaciones Exteriores y Comercio en la cual entregaba "antecedentes importantes sobre la manera que podrá emplearse en nuestro país para atacar la gran invasión de conejos que está produciendo tan graves daños a la agricultura". En este sentido, realizó "un estudio de los sistemas utilizados en Alemania para combatir a los conejos silvestres constituidos en plaga para la agricultura" 42 . A juicio de Vicuña, en Chile, existía "un peligro gravísimo para la agricultura por los perjuicios que vienen ocasionando los conejos, y lo peor es que los agricultores han debido convenir que se hace indispensable no seguir cazando los zorros que son animales que se comen los conejos. Pero hay que tener presente que son mortales enemigos de los corderos y de las aves de corral". Al mismo tiempo, Vicuña envió a la Sociedad Nacional de Agricultura dos modelos de trampas para cazar conejos, con sus precios y también otros catálogos referentes a aparatos para usar gas sulfocarburo, con los precios del aparato y del gas. Finalmente, justificaba la extensión de su informe "en el entendimiento de que dejo tratada una materia que ha de servir a los agricultores, quienes están alarmados con los inmensos daños que reciben de los conejos" 43 .

Reconociendo la plaga, el 8 de marzo de 1932, mediante el oficio $\mathrm{N}^{\circ} 300$, la Dirección General de Pesca y Caza solicitó al Ministro de Fomento la prórroga por cinco años de prohibición de caza de las distintas especies de zorros, entre otras especies nativas, con el objetivo de controlar las poblaciones de conejos ${ }^{44}$. Pocos meses después, el 23 de junio de 1932, se dictó el decreto $\mathrm{N}^{\circ} 1.046$, ante el cual los agricultores de la zona central levantaron numerosos reclamos, pues consideraron que autorizaba bajo ciertas condiciones la caza del zorro, lo que ocasionaría "un grave peligro para la agricultura [...] La extinción o merma de la referida especie significa anular uno de los medios naturales más eficaces para concluir con la plaga de conejos y liebres que invaden los campos con grave perjuicio de la economía nacional". Además, consideraban que, si bien en el decreto 1.046 se fijaban normas para compensar los efectos de la apertura parcial de la caza del zorro, como por ejemplo comercio y exportación de pieles de zorro con la obligación de exportar al mismo tiempo grandes cantidades de pieles de liebres y conejos, "esta compensación no corresponde a la magnitud de los daños que se pueden originar"45. En efecto, la Sociedad Agronómica de Chile había planteado diez días antes, el 13 de julio, la necesidad de mantener la veda absoluta de caza del zorro,

41 Chile. Congreso Nacional. Senado, Sesiones de la Cámara de Senadores, 7 de febrero de $1929,2.748$

42 "Animales dañinos. Procedimientos para exterminar la plaga de los conejos", en Boletín de la Sociedad Nacional de Agricultura, Vol. LXII, No 4, Santiago, abril de 1930, 198.

43 Ibid., 202.

44 AN.FMF, Vol. 653. Expediente Decreto $\mathrm{N}^{\mathrm{o}}$ 1.253, 30 de julio de 1932.

45 Ibid., Vol. 654. Decreto $\mathrm{N}^{\mathrm{o}} 1.205,21$ de julio de 1932. 
argumentando que "el solo hecho de que el zorro sea un enemigo poderoso de una de las más perjudiciales plagas que comienzan a surtir sus efectos en nuestra agricultura, bastaría para tratar de proteger su existencia por todos los medios posibles"46. En estas circunstancias, el Departamento de Pesca y Caza del Ministerio de Fomento optó por la derogación del Decreto $\mathrm{N}^{\circ} 1.046$, manteniendo "en todo su rigor los preceptos de la Ley $\mathrm{N}^{\circ} 4.601$, en cuanto se refiere a la veda de la caza del zorro y demás animales protegidos" 47 . Pocos días después, el Ministerio de Fomento aprobó el Decreto $\mathrm{N}^{\mathrm{o}} 1.253$, mediante el cual prorrogó “por el término de tres años a contar desde el $1^{\circ}$ de diciembre del año en curso, la prohibición establecida en la letra b) del artículo $2^{\circ}$ del reglamento de la ley 4.601 " 48 .

Sin embargo, en 1934, en el valle central la plaga de conejos no cedía. Ese año Carlos Reed publicó un folleto que denominó Aprovechemos la carne y la piel del conejo silvestre y con esto contribuiremos al bienestar nacional, en el que señalaba que

"en los últimos veinte años el conejo en estado silvestre se ha multiplicado extraordinariamente en los campos de Chile, y ya va llegando al sur [...] la agricultura se lamenta de los grandes destrozos que este roedor le ocasiona en sus cultivos [...] yo atribuyo un valor extraordinario desde el punto de vista de la salud de nuestro pueblo, a la aclimatación del conejo en estado silvestre, en los campos de Chile [...] el campesino antes no comía carne [...] ahora con la multiplicación del conejo, la carne entra en la dieta diaria de los campesinos y también de los habitantes de las ciudades"49.

Reed había podido constatar que "más de cien mil conejos muertos, cazados con trampas o con perros, llegan mensualmente durante los meses de invierno, a la ciudad de Santiago, para ser vendidos en los diversos mercados. En un solo día, en el año 1933, según pude informarme, entraron a Santiago más de cinco mil conejos muertos". Por lo tanto, "la carne de conejo se vende a bajo precio en Santiago". Luego recomendaba una serie de recetas de conejo, para concluir que

"el pueblo chileno, haría obra patriótica si consumiera mas carne de conejo y procurara reemplazar, hasta cierto punto, con esta carne, la de vaca, cordero y gallina [...] que su consumo aumente en todos los hogares de Chile y con esto pues disminuirá la plaga de conejos en los campos y el pueblo estará mejor nutrido, habrá menos consumo de carne de vacuno importado y además las pieles de conejos debidamente secadas podrán ser mejor aprovechadas por la industria peletera nacional y también como un articulo importante de exportación" ${ }^{50}$.

El 8 de junio de 1934, los peleteros de Santiago solicitaron formalmente la apertura de la caza de zorros en la zona norte, desde el 15 de junio hasta el 31 de

46 Ibid., Vol. 653. Expediente Decreto $\mathrm{N}^{\circ}$ 1.253, 30 de julio de 1932.

47 Ibid., Vol. 654. Decreto $\mathrm{N}^{\mathrm{o}} 1.205,21$ de julio de 1932.

48 Ibid., Vol. 653. Expediente Decreto $\mathrm{N}^{\circ} 1.253,30$ de julio de 1932.

49 Carlos Reed, Aprovechemos la carne y la piel del conejo silvestre y con esto contribuiremos al bienestar nacional, Santiago, Imprenta y Litografía La Ilustración, 1934, 3.

$50 \quad$ Ibid., 36. 
agosto, y de zorros, coipos y huillines, en la zona sur, desde el primero al 31 de agosto, permitiendo su exportación hasta el 31 de septiembre, argumentando que ello

\begin{abstract}
“contribuiría poderosamente a despertar el interés entre los cazadores de conejos y liebres salvando así a la agricultura de esta plaga y dando salida al mismo tiempo de numerosos cueros de zorros, coipos y huillines que conservan los propietarios y mayordomos, etc., de los fundos. Es de imaginarse que los cazadores de conejos y liebres no dejan de cazar el zorro y otras especies de animales dañinos cuando cruzan el camino. Así que no es extraño que se haya acumulado una gran cantidad de estas pieles, cuyo valor debe aprovecharse debidamente, con beneficio manifiesto para el fisco ya que el comercio y exportación de ellas significan un ingreso considerable de impuestos y derechos de aduanas, y su empleo en el país daría mayor vida a la industria nacional de peletería. Además, se ha visto que la ley de veda y prohibición, durante su vigencia de cuatros años, no ha tenido los efectos de exterminar la plaga de los conejos y liebres, y tal vez, al contrario, la ha dejado tomar mayores proporciones, pues es el caso que cuando se permitía la caza de los zorros, coipos, etc., se exportaban casi 4 millones de cueros de conejos y liebres anualmente, pero que desde que está en vigencia la ley de prohibición, la exportación de liebres y conejos ha sido casi nula. Prueba más elocuente no puede existir para demostrar que la matanza de conejos es fomentada cuando hay una salida de las pieles también, y por lo tanto, estimulando a los cazadores de conejos y liebres al permitirles una salida de las pieles de zorros, coipos, etc., que caen en su poder, se logrará exterminar la plaga de conejos y liebres en los campos agrícolas [...] de este modo se evitaría el ejercicio clandestino de la caza, y a pesar de la vigilancia que se mantiene en las aduanas, se evitaría también que se sigan exportando estas pieles al margen de la ley y a favor de los malos expedientes de que se valen los contraventores para hacerlo, burlando el pago de los derechos respectivos" 51 .
\end{abstract}

Días después los comerciantes y exportadores de cueros para pieles de Talca, solicitaron al Ministro de Fomento la apertura de caza de las especies coipos, huillines y zorros. Esto, considerando el beneficio económico del país a través de los puestos de trabajo y de los ingresos por concepto de impuestos y derechos aduaneros que generaba esta actividad económica. Además, en los seis años de veda, se había conseguido largamente la conservación de estas especies, cual era el objetivo del reglamento de la Ley $\mathrm{N}^{\circ} 4601$ sobre caza del 18 de junio de 1929. Al mismo tiempo, planteaban que "la apertura de la caza de estos animales llevará una ayuda efectiva a muchos hogares de nuestros campesinos azotados por la crisis, ya que los cazadores podrán dedicarse a una actividad que les deja buenas utilidades por los altos precios que ellos perciben por las pieles de estos animales" 52 .

Al respecto, Luis Lagos, director general de la Dirección de Bosques, Pesca y Caza, planteó que la ley de caza respondía a la necesidad de

51 AN.FMF, Vol 885. Expediente Decreto Ley N 2.436 de 11 de agosto de 1934.
Idem. 
"proteger estos animales de la tenaz persecución que venían siendo objeto y evitar la extinción de especies que propagadas en forma conveniente podían llegar a constituir una gran riqueza económica para el país; y por lo que respecta al zorro un elemento de defensa natural a la invasión de las liebres y conejos de las propiedades agrícolas del centro y sur de nuestro territorio. La veda establecida por el reglamento y decretos posteriores se ha mantenido hasta hoy con ligeras excepciones, lo que ha hecho que todos los años, los comerciantes en pieles hayan recurrido al ministerio del digno cargo de US., pidiendo la suspensión temporal de ella en esta misma época, o sea la del invierno, que es cuando los animales de que se trata adquieren la plenitud de su valor en lo que se refiere a la calidad de su pelaje. A este respecto, y toda vez que en las provincias de Coquimbo y Atacama no hay plagas de liebres y conejos que combatir y el zorro, en esa zona, constituye en realidad un peligro para las crías del ganado lanar y cabrío y aun para la especie cada vez más extinguida, de chinchilla, opina esta dirección que no habría inconveniente en otorgar ese permiso hasta el 31 de agosto, próximo, previa inscripción de los cazadores y pago de carné correspondiente en las gobernaciones que procedan [...] en cuanto a lo que se refiere a la caza del zorro en la zona comprendida entre las provincias de Aconcagua al sur, y a pesar de lo que afirman los solicitantes de que la caza de este animal les serviría de estímulo para dar al mismo tiempo una batida en regla a los roedores (liebres y conejos) que invaden los campos, considero que esta materia es digna de un mayor estudio y que para resolverla, sería preciso consultar previamente al Ministerio de Agricultura" 53 .

El informe del Servicio de Sanidad Vegetal del Ministerio de Agricultura recogió la opinión del director de Pesca y Caza al plantear que:

"el zorro era un valioso elemento de defensa natural contra la invasión de liebres y conejos en las propiedades agrícolas del Centro y Sur de nuestro territorio. Los conejos y las liebres son una plaga desde la provincia de Aconcagua hasta la de Cautín, inclusive, de modo que desde este punto de vista todo lo que se haga por conservar los zorros será solamente en beneficio de nuestra agricultura. Los daños que puedan causar estos animales creo que no pueden tomarse en cuenta al lado de los perjuicios causados por los roedores mencionados; además los agricultores pueden fácilmente tomar precauciones para impedir este daño que puedan causar los zorros. La opinión del suscrito con respecto al zorro es por lo tanto que desde la provincia de Aconcagua hasta Cautín inclusive, no se permita su caza, haciéndose por el contrario más estricta la veda existente, a fin de evitar todo comercio clandestino de pieles de zorro. Me permito aun insinuar que deben confiscarse todas las pieles que existen almacenadas en los fundos, de animales cazados durante la veda, y que están en espera de que se abra el permiso para exportar, para poder venderlas. Si no se toma esta precaución los períodos de veda resultan completamente inútiles pues los mayordomos y otros empleados en los fundos continúan cazando zorros y guardan los cueros hasta el momento en que su venta sea permitida. Por lo que respecta a las provincias de Coquimbo y Atacama y al sur de la provincia de Cautín donde el problema de los conejos prácticamente no existe, no veo inconveniente para que se de la autorización pedida" ${ }^{54}$.

\section{Idem. \\ 54 Idem.}


Confirmando lo anterior, la Inspección de los Servicios Provinciales del Ministerio de Agricultura señalaba que los zorros causaban perjuicios considerables en las explotaciones de ovejunos y cabríos y que "no existe la plaga de esos roedores", por lo que sería conveniente que se dictara una ley que "eximiera a las provincias de Atacama y Coquimbo del cumplimiento general de la Ley $\mathrm{N}^{\mathrm{o}} 4.601$, que prohíbe la caza del zorro" ${ }^{55}$. En este contexto, el decreto 2.436, del 11 de agosto de 1934, excluyó de la veda a las provincias de Coquimbo y Atacama y estableció la prohibición de "la captura del zorro en las provincias de Aconcagua a Cautín inclusive" 56 . Sabemos, asimismo, que el 17 de agosto de 1942, la Dirección General de Pesca y Caza recogió diversas informaciones que confirmaban las aseveraciones sostenidas por particulares, quienes señalaban que, en la zona comprendida entre los ríos Mapocho y Maipo, se había desarrollado una plaga de roedores que producía considerables perjuicios. En consecuencia, el 21 de agosto de 1942, se estableció, mediante el decreto 1.745 , la veda absoluta para la caza del zorro por espacio de cinco años en la zona afectada por la plaga de roedores ${ }^{57}$.

Un año después, el 9 de julio de 1943, algunos propietarios de la provincia del Maule plantearon que "la prohibición de la caza del zorro había ocasionado en la provincia del Maule una abundancia de este dañino animal, originando verdaderos estragos en los rebaños de la región. Los perjuicios producidos en el ganado lanar por la plaga de zorros habían alcanzado tales proporciones que los agricultores se encontraban justamente alarmados por este motivo, llegando algunos a suprimir la crianza ante el temor de mayores perdidas". En consideración a "lo expuesto, y en atención a los superiores intereses de la industria nacional, tenga a bien a tomar las medidas precautorias que procedan, teniendo precedente que el principal motivo para prohibir la caza del zorro, ha desaparecido con el notable incremento de la caza de liebres y conejos, dado el alto precio que han alcanzado los cueros de estos animales" 58 . En este sentido, el 31 de julio de 1943, el director general de la Dirección de Pesca y Caza señalaba que el decreto ley $\mathrm{N}^{\circ} 2.436$ efectivamente había dado los resultados esperados. Diez años después, la Dirección de Pesca y Caza del Ministerio de Fomento afirmaba que

"se multiplicaron los zorros en tal abundancia, que, si bien es cierto que se ha logrado reducir la plaga de conejos, a su vez, ya no encuentran alimento suficiente, por lo que se han lanzado a la caza de ganado lanar, como lo asevera el informe Ministerio de Agricultura. Es, por lo tanto, llegado el momento de dar libre la caza del zorro, en la forma como lo establece el reglamento de la Ley de Caza en su articulo $1^{\circ}$, dejando solo subsistente la veda total que establece por espacio de cinco años, el decreto 1.745 , de 21 de agosto de 1942, en la pequeña zona comprendida entre los ríos Mapocho y Maipo"59.

\footnotetext{
55 Idem.

56 Idem.

57 Ibid., Vol. 1968. Decreto Ley 1.745, 21 de agosto de 1934.

58 Ibid., Vol. 15. Expediente Decreto Ley N ${ }^{\circ}$ 618, 16 de agosto de 1943.

59 Idem.
} 
Vistos estos antecedentes, el Ministerio de Fomento dictó el Decreto $\mathrm{N}^{\mathrm{o}} 618$ del 16 de agosto de 1943, que derogó el Decreto $N^{\circ}$ 2.436, manteniendo, eso sí, "la veda ordinaria que contempla el articulo $1^{\circ}$ del reglamento de la ley de caza y la veda extraordinaria establecida por decreto $\mathrm{N}^{\circ} 1.745$, del 21 de agosto de 1942, para la zona comprendida entre los ríos Maipo y Mapocho"60. Lo cual nos indica que los conejos seguían siendo considerados como una plaga para la agricultura en la actual área metropolitana de Santiago.

No obstante, Carlos Schneider realizaba otro diagnóstico para la región del Biobío, al señalar que, si bien los primeros conejos se habían aclimatado en Concepción alrededor de 1907 y habían causados estragos hacia 1909, posteriormente habían desaparecido totalmente, "tal vez controlado por algún carnívoro o ave de rapiña para aparecer nuevamente en los últimos años en forma de una plaga realmente seria" ${ }^{1}$, contradiciendo, en este sentido, lo planteado por el Departamento de Pesca y Caza del Ministerio de Fomento.

Pese a las evidencias de lo sucedido con los conejos en Chile central, el 26 de junio de 1940, la Dirección de Pesca y Caza ingresó un proyecto a la CORFO para poblar las islas australes con conejos, liebres y cabritos, para luego soltar zorros plateados, azules, grises y colorados y formar así "una fuente inagotable de riquezas con animales de piel fina" 62 . En marzo de 1943, la revista Pesca y Caza publicó un artículo denominado "Seis puntos impostergables en la caza y pesca de Chile", en el cual se insistía en el proyecto de incorporar las innumerables islas australes a la economía, poblándolas de liebres, conejos y cabritos, para después de algunos años, cuando esos animales se hubiesen multiplicado, largar

“zorros plateados, azules y grises y otros animales de piel fina, una especie en cada isla, donde encontrarían el alimento necesario para su sustento, en forma de liebres, conejos y cabritos. Una vez que se hubieren multiplicado esos animales pelíferos, sería llegado el momento de la labor directa del hombre, quien, desde el primer día encontraría animales que le proporcionarían valiosas pieles y ganancias consiguientes inmediatas" 63 .

Rafael Housse, por su parte, señalaba que el zorro culpeo se alimentaba de "los mamíferos de reducido tamaño incapaces de resistirles: todas las especies de ratas, liebres y conejos de cualquiera edad, vizcachas, cabritos, corderos, pudúes y casualmente gatos domésticos". Según Housse, los posibles daños que podía causar el zorro culpeo en los animales domésticos que devora:

“en realidad no son muchos sus estragos, por lo mismo que la especie vive comúnmente en partes apartadas y silvestres que no frecuentan el ganado menor y que distan de las

60 Idem

61 Carlos Schneider, "Catálogo de los mamíferos de la provincia de Concepción”, en Boletín de la Sociedad de Biología de Concepción, tomo XXI, Concepción, 1946, 76.

62 AN.FMF, Vol. 1976. "Repoblación de las islas australes".

63 "Detengamos el exterminio de nuestras especies", en Pesca y Caza, Año II, N" 2, Santiago, marzo de 1943,28 . 
viviendas humanas. Estos daños son muy inferiores a los beneficios que el culpeo reporta al hombre por la cantidad enorme de liebres y conejos, crías y adultos, que destruye preservando los campos de los destrozos. Así lo proclama la experiencia: donde la gente inconsiderada ha mermado o exterminado a los culpeos, allí cundieron en tal forma los conejos y liebres que inutilizaron las siembras y acabaron con los cultivos. Lo propio sucedió en la cuenca del río Claro, al este de Molina, en los años 1928-1930. Por codiciar el valor comercial de las pieles dedicándose los montañeses a la matanza de culpeos, de resultas de esa aberración los leporidos se multiplicaron de tal forma que invadieron las laderas y quebradas cordilleranas y rebasaron el valle central, siendo incontenible tan funesta plaga" ${ }^{64}$.

Never Bonino y Reinaldo Gader señalan, por su parte, que entre 1945 y 1950 se vieron por primera vez conejos en Argentina, en la provincia de Neuquén y más precisamente en la localidad de Andacollo. Los autores plantean que estos conejos "provinieron casi con seguridad de Chile, ya que en el sector chileno a igual latitud, se encontraban establecidas poblaciones de esta especie, y en esta zona existen numerosos pasos que cruzan la cordillera con una altitud que de ninguna manera constituye un impedimento para el avance de los conejos" 65 . Por su parte, John Keever Greer realizó observaciones de mamíferos en la provincia de Malleco entre 1960 y 1962 y estimó que el conejo se distribuía "a todo lo largo de la provincia de Malleco, exceptuando las partes altas de la cordillera de los Andes" $" 66$.

Por otra parte, las estadísticas sobre pieles de conejos y zorros exportadas por Chile nos indican que efectivamente disminuyó el número de pieles de zorro enviadas al extranjero, lo cual es evidencia de una menor cacería, producto de las restricciones impuestas por la ley de caza de 1929. Sin embargo, el número de pieles de conejos exportadas aumentó notablemente, al menos hasta la década de 1960, alcanzando un máximo de 479.031 pieles exportadas en el período 19501954. En este sentido, los números indican que no existiría una correlación directa entre el aumento de la población de zorros y la disminución de la población de conejos, pues a pesar de disminuir la exportación de pieles de zorros, la exportación de pieles de conejos fue en aumento. Esto obedecería, con los antecedentes disponibles hacia 1960, a dos factores señalados en este trabajo. Por un lado, el fomento de la cunicultura mencionado precisamente para aquel período y, por otro, la expansión de la presencia del conejo silvestre en Chile central.

64 Rafael Housse, Animales Salvajes de Chile en su clasificación moderna, Santiago, Universidad de Chile. 1953, 150-153.

65 Never Bonino y Reinaldo Gader, "Expansión del conejo silvestre europeo (Oryctolagus cuniculus L.) en la República Argentina y perspectivas futuras", en Anales del Museo de Historia Natural de Valparaíso, $\mathrm{N}^{\mathrm{0}} 18$, Valparaíso, 1987, 157.

66 John Keever Greer, Mamíferos de la provincia de Malleco, Angol, Museo Dillman S. Bullock, 68 y 69 . 
TABLA 1

NÚMERO DE PIELES EXPORTADAS, 1910-198067

\begin{tabular}{lrr}
\hline Años & Conejos & Zorros \\
\hline $1910-1914$ & 0 & 96.524 \\
$1915-1919$ & 0 & 14.418 \\
$1920-1924$ & 0 & 19.176 \\
$1925-1929$ & 453.775 & 53.367 \\
$1930-1934$ & 68.315 & 24.059 \\
$1935-1939$ & 75.989 & 21.827 \\
$1940-1944$ & 151.739 & 25.904 \\
$1945-1949$ & 159.655 & 9.692 \\
$1950-1954$ & 479.031 & 2.404 \\
$1955-1959$ & 255.621 & 2.845 \\
$1960-1964$ & 273.719 & 17.893 \\
$1965-1969$ & 120.270 & 14.704 \\
$1970-1974$ & 37.000 & 11.100 \\
$1975-1979$ & 51.645 & 1.746 \\
$1980-1984$ & 14.600 & 0 \\
Total & & 315.659 \\
\hline
\end{tabular}

Lo sorprendente de esta historia es que, aproximadamente treinta años después, Jaksic y Yáñez calcularon, por primera vez, la incidencia de los conejos en la dieta de los zorros chilenos, a partir del análisis de fecas y estómagos de carnívoros y de regurgitados de aves rapaces, concluyendo que los conejos constituían una fracción minoritaria de las presas cazadas por los predadores más comunes en el país. Como explicación de este fenómeno, planteaban que los predadores chilenos no eran eficientes en la caza del conejo, pues no habían desarrollado las "adaptaciones conductuales para cazar una especie recientemente introducida como era el conejo. En todo caso cualquiera sea la explicación al fenómeno, es aparente que los predadores no tienen un rol importante en la abundancia de conejos en Chile" 68 . Con esto aniquilaban varios años de políticas públicas en la materia y planteaban un nuevo desafío: ¿cómo controlar la plaga de conejos?, ¿qué hacer para evitar los perjuicios que causa a la agricultura?

67 José A. Iriarte y Fabián M. Jaksic, "The fur trade in Chile: an overview of seventy years of export data (1910-1984)", en Biological Conservation, Vol. 38, Barking, 1986, 247.

68 Fabián M. Jaksic y José Yáñez, “QQuién controla las poblaciones de conejos introducidos?”, en Medio Ambiente, $\mathrm{N}^{\circ}$ 4, Valdivia, 1980, 43. 
Desde otro punto de vista, solo nos queda plantear que, a pesar de este equivocado y reiterado pensamiento analógico, que trasplantaba el rol de los zorros españoles en el control de los conejos peninsulares a la capacidad intrínseca de los zorros chilenos para controlar la plaga de esta especie exótica en el país, las especies de zorros nacionales posiblemente fueron resguardadas por las instituciones del Estado, permitiendo, al menos, disminuir el proceso de extinción en que se hallaban antes de la ley de pesca y caza de 1929. Efectivamente, como lo denotan las demandas de los cazadores del valle central, con esta ley se puso una serie de cortapisas para la exportación de pieles de zorros, que se redujo sustantivamente tal como lo demuestra la estadística en la Tabla 1. Así, el mito que ha reputado a los zorros chilenos como voraces comedores de conejos, se construyó sobre la base de suposiciones y no sobre una plataforma científica con datos cuantificados sobre la dieta efectiva de estos depredadores. En todo caso, afortunadamente esta suposición y mitificación permitió la aplicación más férrea de una institucionalidad que reguló la caza del zorro y de otras especies en el país y que intentó impedir o dificultar al máximo la exportación de sus pieles, a raíz, en este caso, del supuesto rol ecológico que cumplían.

\section{CONEJOS EN TIERRA DEL FUEGo}

Otra plaga de conejos conocida en el país fue la ocurrida en la región fueguina de Magallanes. Pedro Arentsen señala que los primeros conejos fueron introducidos en la Isla Grande de Tierra del Fuego, hacia 1874, por misioneros protestantes que se instalaron en la parte argentina de la isla, enfrentando el canal Beagle. Estos primeros ejemplares se habrían multiplicado libremente, en una vida completamente silvestre, pero al cabo de poco tiempo habrían sido diezmados por un invierno muy crudo, de fuertes heladas y nevazones. En 1913, se habrían liberado nuevamente conejos en el sector chileno de Baquedano y poco después en las proximidades de Porvenir, pero debido a los duros inviernos ninguno de estos ensayos habría prosperado, para suerte de la ganadería fueguina de entonces. La plaga de 1950 provino de dos parejas de conejos de origen europeo largados en los alrededores de Porvenir, por el año 1936, o quizás dos o tres años antes. Estos conejos se habían "multiplicado rápidamente sin dársele mayor importancia al hecho, debido a que tanto los ganaderos como los obreros veían en el aumento de su población una nueva fuente de riqueza para la provincia"69.

69 Pedro Arentsen, "Control Biológico del Conejo", en Boletín Ganadero, No 43, Punta Arenas, $1954,4$. 
TABLA 2

EMBARQUE DE CUEROS DE CONEJOS AL NORTE DEL PAÍS, PROCEDENTES DE LA PROVINCIA DE MAGALLANES ${ }^{70}$

\begin{tabular}{lrr}
\hline Año & Piezas & Valor \$ \\
\hline 1939 & 4.171 & 15.732 \\
1940 & 4.318 & 13.564 \\
1941 & 10.624 & 64.877 \\
1942 & 51.121 & 422.074 \\
1943 & 148.289 & 1.216 .495 \\
1944 & 120.045 & 1.464 .811 \\
1945 & 89.793 & 772.961 \\
1946 & 185.337 & 2.564 .440 \\
1947 & 318.031 & 4.159 .150 \\
1948 & 433.340 & 3.504 .286 \\
1949 & 379.490 & 3.203 .472 \\
\hline
\end{tabular}

Como se puede apreciar en la Tabla 2, junto con la plaga de conejos en los campos fueguinos, el comercio de esta especie adquirió un desarrollo creciente a partir de 1942, reportando generosas ganancias, especialmente para quienes se dedicaban al comercio de las pieles. Sin embargo, Arentsen señalaba

"mucho se ha dicho y se ha escrito sobre la conveniencia de que se tomen medidas que tiendan a proteger la libre multiplicación de los conejos alegándose los beneficios que este roedor aporta a la economía de un país, tanto por las carnes como por las pieles que producen y que significan un elemento de trabajo, para los cazadores y el desarrollo de industrias que explotan estos ramos [...] Estos beneficios aparentes para un país son indiscutiblemente muy relativos si se consideran los enormes daños que ocasionan estos leporidos"71.

Desde principios de 1947 , la plaga de conejos que azotaba a la provincia comenzó a preocupar seriamente a la directiva de la Unión de Pequeños Ganaderos de Magallanes, que se dirigió por primera vez al Ministerio de Agricultura "representándole la gravedad de esta plaga y la amenaza inmediata que ya constituía para la ganadería de Magallanes"72. H. B. de Bruyne fue uno de los primeros particulares que advirtió a los ganaderos y a las autoridades del verdadero alcance económico de esta terrible plaga, al comentar en La Prensa Austral del 19 de junio de

\footnotetext{
70 "Exterminación total de la plaga de conejos", en Boletín Ganadero, Año I, No 8, Punta Arenas, septiembre de 1950, 3 .

71 Arentsen, op. cit., 8.

72 Daniel Claro, "Instituciones ganaderas aúnan sus esfuerzos para extirpar la plaga de conejos en la región”, en Boletín Ganadero, Año I, N 3, Punta Arenas, enero de 1950, 24.
} 
1948, un pertinente artículo titulado "Una advertencia a Chile", escrito por el señor Jorge Mulgrue y aparecido en la revista Imperial Review. Este artículo, Mulgrue planteaba que:

“el conejo no consume solamente la vegetación de pastoreo que aflora a la superficie, sino que también come el corazón de la planta, de tal manera que esta muere, convirtiendo en eriales lo que antes eran verdes praderas. Además, el conejo no come cualquiera planta, se alimenta únicamente de los mejores pastos de cada región, dejando subsistir las malezas, que terminan por extirpar el pasto aprovechable que no consumieron los conejos. La bosta de los conejos, por otra parte, envenena y mata los pastizales transformando los campos por ellos asolados en terreno árido, que, a falta de árboles para evaporar la humedad pueden dar lugar a desastrosas sequías. La falta de vegetación ocasionada por estos roedores, añadida a la inevitable sequía que dicha falta significa, acarrean la erosión del terreno, de tal manera que, en corto tiempo, los campos atacados de conejos se convierten en arenales movibles. Es del caso llamar seriamente la atención hacia lo que esto puede significar en una región de fuertes vientos, como lo es la Patagonia Chilena. El alimento requerido por un lanar satisface solo a 16 conejos. Si consideramos que una pareja de conejos, con un número normal de pariciones que alcanza, por lo menos, a cuatro por año, se convierte al cabo de un año en millones de ejemplares, veremos que el peligro de no contar con el pasto suficiente para el ganado lanar puede ser una triste realidad dentro de un plazo relativamente corto"73.

Por su parte, Manuel Chaparro, presidente de Unión de Pequeños Ganaderos de Magallanes, planteaba que si “este mal continúa dentro de cinco o diez años se habrá terminado la capacidad talajera de Tierra del Fuego hasta sus raíces, iniciándose la erosión de los suelos que hará de toda la provincia un gran desierto"74. Asimismo, señalaba que Carlos Strauss, de reconocida experiencia en asuntos zoológicos, le había expresado que "la plaga de conejos tenía su origen en un desequilibrio producido en la naturaleza con la caza descontrolada de animales de pieles finas [...] dijo que había que ir hacia una protección de nuestra fauna como manera de impedir la desaparición de las especies que se alimentan de conejos y no permiten que la especie aumente en forma desproporcionada"75. En la misma dirección, otro autor señalaba que

"desde hace varios años a esta parte y debido a la caza implacable y sin control y el libre comercio de cueros, plumas, pelos de zorros, chingues, quiques, gatos monteses y pajeros, águilas, aguiluchos, etc., se ha ocasionado la desaparición de estas especies y la multiplicación desmedida de otras como ser el conejo cuya multiplicación es asombrosa con el consiguiente desequilibrio de la naturaleza, originando la verdadera plaga del conejo que está talando todos los campos destinados a la crianza de los ovejunos"76.

\footnotetext{
73 Jorge Mulgrue, "Una advertencia a Chile", en La Prensa Austral, Punta Arenas, 19 de junio de

74 "Plaga de Conejos invade Tierra del Fuego", en Boletín Ganadero, Año I, No 5, Punta Arenas, abril de 1950,2 .

75 Idem.

76 “Campaña nacional contra plaga de conejos", en Boletín Ganadero, Año I, N 7, Punta Arenas, julio de $1950,21$.
} 1948. 
Con estos argumentos, la Unión de Pequeños Ganaderos de Magallanes acordó "gestionar ante los organismos oficiales la dictación de un decreto que contemple la veda de la caza de chingues, zorros grises, gatos salvajes, monteses y pajeros, especies que se han ido agotando en la provincia y que podrían contribuir al extermino del conejo"77.

En Santiago, mediante el oficio No 255, del 24 de mayo de 1950, el Ministro de Agricultura, a través de la Comisión Nacional de Protección a la Vida Silvestre, solicitó al Ministerio de Economía atender "una sugerencia del Comité Local de Magallanes en el sentido de dictar un decreto que prohíba, por un plazo no inferior a cinco años, la caza y el comercio de pieles, pelos y plumas de varias especies animales que son enemigas del conejo"78. El oficio fue derivado por el ministro de Economía al Departamento de Pesca y Caza. El 6 de junio de 1950, Exequiel Rodríguez, su director, elevó al ministro de Fomento una solicitud de decreto que prohibía la caza de todas las especies enemigas del conejo, con el objetivo de “combatir la plaga de dichos animales, que está ocasionando tan graves perjuicios a la ganadería de la región de Magallanes y Aysén a causa del desequilibrio biológico producido por la persecución incontrolada, especialmente de zorros y gatos monteses". Al mismo tiempo recomendaba, para combatir la plaga de conejos, que se aprovechase su carne congelada en los frigoríficos de esa zona, enviándola a la zona central, con lo cual aumentaría en forma notable la caza de esta especie. Se encomendaba, asimismo, al representante de la Asociación Ganadera de Magallanes que adquiriese en la zona comprendida entre Concepción y Puerto Montt y con los fondos disponibles para esta campaña, parejas de zorros para soltarlos en Tierra del Fuego ${ }^{79}$.

Acogiendo el llamado de la Unión de Pequeños Ganaderos de Magallanes y el informe técnico del Departamento de Pesca y Caza, el 23 de junio de 1950, el ministro de Economía, consideró que la plaga de conejos había causado perjuicios de importancia a la masa ganadera de esa zona y que este aumento en el número de conejos se debía a la caza y exterminio de algunas especies que eran enemigas del conejo. En consecuencia, acordó prohibir por el término de cinco años "la caza y el comercio de pieles, pelos y plumas o huevos de las siguientes especies consideradas enemigos del conejo, en las provincias de Aysén y Magallanes: águila, aguilucho, avestruz ñandú, cernícalo, Chilla o zorrino patagónico, chingue, gato montés, güiña o gato montés chico, guanaco, quique, peucos" 80 . Asimismo, el 7 de agosto de 1952, el Ministerio de Agricultura dictó el Decreto Supremo No 811, que declaró al conejo plaga de la agricultura en Magallanes y obligó a su combate, y el 24 de agosto el Decreto Supremo $\mathrm{N}^{\circ} 1.379$, que estableció como medida efectiva el uso de medallas de alambre ${ }^{81}$.

\footnotetext{
77 "Labor Directiva", en Boletín Ganadero, Año I, Nº 6, Punta Arenas, mayo de 1950, 23.

78 AN.FMF, Vol. 280, Expediente Decreto Ley N ${ }^{\circ} 757,13$ de julio de 1950.

79 Idem.

80 Ibid., 23 de junio de 1950.

81 Arentsen,op. cit., 6.
} 
En diciembre de 1953, comenzó el combate biológico del conejo, empleando para este efecto el virus de una enfermedad que había probado ser específica del conejo: la myxomatosis. Para 1954 se proyectaba una campaña que inyectaría el virus a 100.000 conejos. Luego se procedería a exterminar todos los focos aislados que pudieran quedar, empleándose para ello toda clase de elementos, como sebos, venenos, gases, perros, predadores, armas de fuego, etc. ${ }^{82}$. En este marco, en 1954, el Departamento de Ganadería y Sanidad Animal de Magallanes, bajo la jefatura del médico veterinario Elías Sabat, inició una enérgica campaña contra la plaga del conejo. Brigadas de inoculación del virus myxomatósico, audiciones radiales dedicadas a la nefasta plaga y el apoyo de Carlos Aracena, director del diario La Prensa Austral ${ }^{83}$. En todo caso, Sabat manifestaba sus aprensiones y dudas sobre el proceso, advirtiendo que la mixomatosis:

"no era una panacea infalible ya que había estudios efectuados por bacteriólogos e inmunólogos que comprobaban que se podía producir en el animal una resistencia bastante notable al virus y cuando lleguemos a este estado de cosas deberemos recurrir a todos los medios posibles como son los perros, armas de fuego, venenos, etc. y establecer el equilibrio natural de la isla mediante los predadores que atacan al conejo y la acción del hombre para llegar a un control efectivo de la plaga. En las circunstancias actuales parece necesario, en forma imperativa, la colocación de mallas para defender tanto los campos erradicados, como así también, para continuar la lucha en áreas más pequeñas, haciéndose de esta manera más efectiva la infestación y mortalidad de los conejos" 84 .

Lo mismo estimaba Arentsen, quien pudo

"observar en viajes de recorrido en campos de la estancia "Sarita", de la sociedad ganadera Gente Grande, donde la epizootia había prácticamente barrido con numerosos roedores en pocos meses, que numerosos ejemplares seguían viviendo tranquilamente en el sector amagado y en circunstancias de que estaban rodeados de animales enfermos o muertos por myxomatosis. Estas observaciones dan margen a pensar que los conejos de Tierra del Fuego ya están comenzando un proceso de inmunización" ${ }^{85}$.

En abril de 1954, se realizó un foro público en la región, para analizar la situación de la plaga de conejos, que amenazaba con "terminar, a corto plazo, las fértiles praderas de la isla Grande de Tierra del Fuego" 86 . Al respecto, Otway Falkiner, criador de ovejas de Australia, señalaba con vigor: "yo aconsejaría a todo

82 Ibid., 22.

83 "Campaña enérgica contra la plaga de conejos", en Boletín Ganadero, Año IV, N ${ }^{\circ} 44$, Punta Arenas, diciembre de 1954, 10.

84 Elías Sabat, "La mixomatosis no es una panacea infalible", en Boletín Ganadero, No 45, Punta Arenas, 1955, 23.

85 Arentsen, op. cit., 14

86 "Foro público contra la plaga del conejo", en Boletín Ganadero, Año IV, No 40, Punta Arenas, abril de 1954, 8 . 
aquel que viera conejos en sus campos o vecindad que persiga intensamente a los mismos para destruirlos sin piedad"87. Marco Davisón, director de la Unión de Pequeños Ganaderos de Magallanes, por su parte, recordaba que el conejo había llegado hace algunos años y se debía solamente al "espíritu aventurero y deportista exótico" de un hombre que, para

"producirse distracción de caza fácil y abundante se le ocurrió traer a esta región unas parejitas de conejos, largándolas al campo y ahora nos hallamos ante el pavoroso hecho de que se pueden estimar en millones, es decir, 10 conejos por cada oveja, el año que viene ya habrá 20 conejos por cada oveja y a los años de 20 a 40, de modo que si no se toman cartas en el asunto de inmediato se puede adelantar que Tierra del Fuego se transformará en muy breve plazo en una bola de billar" 88 .

La situación era percibida por los ganaderos de Tierra del Fuego como de "extrema gravedad". El conejo había afectado los campos, que presentaban "claros signos de erosión, en algunos casos, y si bien es cierto, esta erosión apenas se insinúa no es menos cierto que terminaran por erosionarse en forma definitiva de continuar de esta manera". Por otra parte el conejo también había afectado a la población ovina, pues

“en la lucha biológica entre el ovino y el conejo, gana este último siempre, ya que está favorecido por una larga lista de factores, como ser su gran proliferación, gran rusticidad, gran sanidad y aún la misma viveza del animal. De esta manera afectó a la población ovina, disminuyendo su número, disminuyendo su producción, disminuyendo su calidad zootécnica en un 20,30, 40 y más por ciento según los casos”.

Además, había afectado a la ganadería, al disminuir todas las faenas: esquila, marca, arreos, frigoríficos, embarques, etc. Así concluía que "el daño causado por la plaga de conejos es difícil de establecer y lo que es peor es difícil de reparar. En 1935 no había conejos en la isla, en menos de 20 años han llegado las cosas a tal extremo, que la ganadería va camino a desaparecer"89.

Entre los factores que favorecían el desarrollo de la plaga se hallaban los hábitos de caza, pues la piel de conejo que tenía valor comercial era la de invierno, por lo que entre mayo y septiembre había muchos interesados en dedicarse a la caza del conejo, pues alrededor de su piel se movían fuertes capitales. A partir de octubre y durante el verano, la piel dejaba de tener el valor comercial que tenía durante el invierno y por esta razón no había interesados en la caza del conejo, lo cual lo transformaba rápidamente en plaga ${ }^{90}$. La situación se tornaba cada vez más desesperada, pues todas las medidas tomadas resultaban ser ineficaces. Entre 1953

87 "Opiniones de Mr. Falkiner y un llamado de atención sobre la plaga de conejos", en Boletín Ganadero, Año IV, Nº 40, Punta Arenas, abril de 1954, 25.

88 Ibid., 26.

89 "Interesante exposición sobre la plaga de conejos", en Boletín Ganadero, Año IV, No 41, Punta Arenas, abril de 1954, 5.

90 Idem. 
y 1954, la región había visto mermada o disminuida su producción en 1.898 .593 kilos de lana, el menor beneficio de animales de una temporada a otra era de 112.003 animales y la disminución de los kilos de carne ascendía a la ya importante suma de 1.947.776 kilos del producto congelado ${ }^{91}$.

No obstante, a partir de 1955, la plaga de conejos se apaciguó en Magallanes, y, desde entonces, dejó de ser un tema para los ganaderos locales. Con el paso del tiempo y con una mirada científica del tema, Jaksic y Yáñez plantean que la introducción del virus myxomatosis fue el más efectivo agente para el control biológico de los conejos en Tierra del Fuego ${ }^{92}$. Sin embargo, hay una opinión disidente, de Ojeda, González y Araya, quienes estimaron que la myxomatosis no logró la erradicación, ya que el conejo desarrolló una resistencia genética, a partir de la cual la población de conejos recuperó su densidad y condición de plaga ${ }^{93}$. Con todo, según observaciones personales de Jaksic, esto no es efectivo, por lo que la myxomatosis persiste como el más efectivo método de control de conejos en Tierra del Fuego.

\section{Conejos en JuAn FernándeZ}

Las 9.290 hectáreas del archipiélago de Juan Fernández fueron declaradas parque nacional en 1935, el cual se encuentra bajo la tutela administrativa de la Corporación Nacional Forestal. En 1977, el archipiélago fue nombrado por la UNESCO como Reserva Mundial de la Biosfera, reconociendo de esta manera este valioso ecosistema que se caracteriza por el alto grado de endemismo de sus especies vegetales. A pesar de encontrarse protegido y bajo la administración de CONAF, Francisco Sáiz y Patricio Ojeda señalan que la isla Robinson Crusoe "ha sido campo de las más inverosímiles introducciones de especies, muchas de las cuales se han convertido en graves plagas, transformando profundamente el ambiente de la isla, tales como ganado doméstico, zarzamora, maqui, trun, zorzal, cabra, coatí, conejo, etc." 94 . Entre estas invasiones a la isla, Sáiz y Ojeda destacaban los conejos, que eran importantes cooperadores de la acción de deterioro ejercida por el ganado, así como otros factores, tales como la construcción de caminos vehiculares, la corta de árboles y la introducción de otras especies animales y vegetales.

Las informaciones disponibles indican que el conejo europeo (Oryctolagus cuniculus), fue introducido en la isla Robinson Crusoe en la década comprendida entre 1930 y 1940 , más precisamente en $1935^{95}$ o $1936^{96}$, con la finalidad de criar

91 "Campaña enérgica contra la plaga del conejo", op. cit., 11.

92 Fabián M. Jaksic y José Yáñez, "Rabbit and fox introductios in Tierra del Fuego: History and assessement of the attemps at biological control of the rabbit infestation", en Biological Conservation, Vol. 26, Barking, 1983, 374.

93 CONAF, "El conejo silvestre en Chile", en Boletín Técnico No 8, Santiago, 1973.

94 Francisco Sáiz y Patricio Ojeda, "Oryctolagus cuniculus L. en Juan Fernández. Problema y control”, en Anales del Museo de Historia Natural de Valparaíso, Valparaíso, Vol. 19, 1988, 91.

95 Walter Kahler, "La isla Juan Fernández", en En Viaje, N 238, Santiago, 1953, 15.

96 Maura Brescia, Mares de leyenda, Santiago, s/1, 1979, 95. 
en cautiverio esta especie y utilizarla como suplemento alimenticio para la población local. Sin embargo, algunos individuos escaparon, expandiendo su distribución por las islas Robinson Crusoe y Santa Clara ${ }^{97}$. Hacia 1970 la situación todavía no parecía grave. Al menos así lo indicaban las observaciones realizadas a principios de 1970 por Daniel Torres y Anelio Aguayo, quienes planteaban que:

"este lagomorfo asuela la vegetación que cubre los suelos de algunos lugares de Robinson Crusoe, tales como "Puerto Inglés", "Puerto Francés", "Villagra" y "Plazoleta del Yunque". En Alejandro Selkirk los isleños aseguran haber visto algunos hace años. Nosotros tratamos de comprobar la posible presencia de estos animales recorriendo gran parte de la isla, con resultado negativo. Por otra parte, constatamos la presencia de gatos domésticos en estado salvaje, por lo que estimamos difícil encontrar conejos en la actualidad. Sin embargo, Mann asegura haber observado algunos ejemplares en las cercanías de la "Quebrada de las Casas", animales que habrían sido introducidos recientemente por los isleños con el objeto de practicar la caza. Actualmente en la isla Santa Clara existe una gran población de conejos, los que son naturalmente controlados por el "nuco" (Asio flammeus suinda)"98.

Sin embargo, cinco años después, en 1975, la percepción de Guillermo Mann era radicalmente distinta al afirmar que el conejo:

"actualmente está representado por muchos miles de ejemplares en la isla Robinson Crusoe. Representa por su continuo aumento, uno de los problemas más graves para el equilibrio biológico en esta isla, pues contribuye en gran medida a la continua disminución del estrato herbáceo y al consiguiente aumento de la erosión. Además contribuye al exterminio de varias especies vegetales autóctonas y aún endémicas. La intensa caza de que es objeto por parte de los isleños no se hace notar en una disminución significativa de su población" $" 99$.

Por su parte, en 1976, el Plan de Manejo Parque Nacional Juan Fernández indicó que el conejo "se encuentra formando grandes poblaciones que contribuyen significativamente al deterioro de la cubierta vegetal, en las islas Robinson Crusoe y Santa Clara y en reducido número en Alejandro Selkirk"100. En todo caso, a finales de la década del 70, la situación se hacía cada vez más insostenible. En 1981, Guillermo Mann señalaba que

"en las islas Santa Clara y Robinson Crusoe, su población es muy numerosa aproximadamente 7.000 ejemplares como promedio y fluctúa grandemente año tras año, repre-

97 Patricio Ojeda, Hernán González y Guillermo Araya, "Erradicación del conejo europeo (Oryctolagus cuniculus Linnaeus, 1758) desde la Isla Santa Clara, Archipiélago de Juan Fernández”, Informe Técnico $\mathrm{N}^{\circ} 48, \mathrm{CONAF}$, diciembre de 2003.

98 D. Torres y A. Aguayo, "Algunas observaciones sobre la fauna del archipiélago de Juan Fernández", en Boletín de la Universidad de Chile, N 112, Santiago, junio de 1971, 34.

99 Guillermo Mann, "Observaciones sobre el estado actual de algunos representantes de flora y fauna en el Parque Nacional Juan Fernández”, en Boletín del Museo Nacional de Historia Natural, N $^{\circ}$ 34, Santiago, 1975, 211.

100 CONAF, Plan de Manejo Parque Nacional Juan Fernández, CONAF, 1976. 
sentando plagas importantes cuando alcanza su máximo número poblacional. En la competencia con el ganado, por la cubierta herbácea, y debido a la confección de galerías que -derrumbándose constantemente bajo las pisadas del ganado- facilitan la erosión física del suelo; su acción destructiva se ve potenciada"101.

Progresivamente, los conejos comenzaron a competir por alimentos con el ganado ovino presente en la isla de Santa Clara, lo que llevó a la comunidad isleña a solicitar la intervención de las autoridades en la solución del problema. En este marco, la Corporación Nacional Forestal (CONAF) convocó a la comunidad científica nacional para efectuar un estudio, cuyo objetivo fue evaluar la magnitud del problema y proponer un plan integral para su control ${ }^{102}$. Como resultado de este estudio, durante 1982, la CONAF recibió el documento "Proposición de un método de control integrado del conejo en el Archipiélago de Juan Fernández”, realizado por un equipo interdisciplinario perteneciente a la Universidad Católica de Valparaíso. La propuesta fue implementada parcialmente durante el período 1983-1985, a través de un programa de caza permanente mediante lazos o huachis, para lo cual se incluyó en el proyecto la contratación de un cazador experimentado, quien se constituyó en un elemento valioso, al capacitar a varias generaciones de cazadores, pues permaneció en la isla hasta su muerte el año 2002.

Evaluaciones realizadas hacia fines de la década de los ochenta evidenciaban una clara recuperación del estrato herbáceo, en sectores donde los conejos habían disminuido, y su mantención o disminución en aquellas zonas en las cuales se habían incrementado. Si bien, en términos globales, no se podía afirmar una disminución de la densidad de conejos, sí era posible plantear una significativa disminución de tallas y pesos, desapareciendo especialmente los individuos más grandes, que tienen mayor tasa reproductora. En consecuencia, "la población de conejos ha sido efectivamente impactada por la caza a que ha sido sometida", lo cual, según Sáiz y Ojeda, avalaría la efectividad de la caza como modalidad de control del conejo, sin necesidad de introducir myxomatosis, "si se aplica el método en forma rigurosa e intensa en toda la isla por un lapso adecuado"103.

No obstante, una década después, en diciembre de 1997, se aprobó un proyecto financiado por el Reino de los Países Bajos que incluyó, en su marco de acción, el control de la plaga de conejos, entre otras. Es así como, a partir de 1998, se inició el Programa de Control del Conejo en las Islas Robinson Crusoe y Santa Clara. Poco después, en el año 2002, se puso en práctica un sistema integrado de control del conejo, con el objetivo de erradicarlo de la isla Santa Clara, que consideró todos aquellos métodos de control en uso en el mundo, con características legal y ecológicamente aceptables ${ }^{104}$. En aquel período, CONAF, pagaba a los cazadores de Juan Fernández 500 pesos por cada cola de conejo que llegara hasta sus dependen-

101 Guillermo Mann, “Análisis del Plan de Manejo y situación actual del Parque Nacional Juan Fernández”, Informe CONAF, 1981, 34.

102 Sáiz y Ojeda, op. cit., 91.

103 Idem.

104 Ojeda, González y Araya, op. cit. 
cias, ya que la plaga de conejos dañaba severamente las especies nativas de las islas, destruyendo plántulas y brotes tiernos ${ }^{105}$.

En el año 2005, la CONAF buscaba financiamiento en el Fondo del Medio Ambiente Mundial de las Naciones Unidas, para realizar estudio por un monto de 1,6 millón de dólares, cuyo objetivo era fijar acciones para conservar la flora y fauna nativa en peligro de extinción en la isla y erradicar a los animales que amenazaban la biodiversidad local. Según explicaba el director de CONAF de la V Región, Mario Gálvez, la primera parte de la iniciativa consistía en realizar una evaluación del estado de conservación de las especies y ecosistemas terrestres y marinos del archipiélago. Por otra parte, se buscaba proponer un modelo para erradicar estas especies, por medio de capturas cuya efectividad sea superior a las capacidades de reproducción ${ }^{106}$. En octubre de 2005, Aarón Caviedes y Guillermo Araya señalaban la importancia de este proyecto, pues el archipiélago albergaba un alto porcentaje de especies endémicas que transformaban al lugar en uno de más ricos del planeta en cuanto a biodiversidad. En particular, una de las principales preocupaciones la constituía la presencia del conejo, que incluso había llegado hasta las partes más altas de la isla, es decir, a las zonas las mejor conservadas. En este sentido, el guardaparque de CONAF Guillermo Araya señalaba que, "en lugares de difícil acceso como El Yunque, se han encontrado muestras de fecas, lo que es un indicador de su presencia"107.

Después de más de setenta años desde su introducción, los conejos siguen asolando el archipiélago y causando graves perjuicios a los ecosistemas isleños, con su variada gama de especies endémicas. Evidentemente, la caza ha demostrador ser insuficiente como método de control de los conejos en las islas Juan Fernández.

\section{CONEJOS EN PLANTACIONES FORESTALES}

En 1968, un estudio realizado por expertos de la Universidad de Chile, sobre la base de una encuesta a las asociaciones y clubes de la Federación de Pesca y Caza, planteó que la distribución de los conejos se había extendido desde Coquimbo al sur, excepto en las provincias de Osorno, Chiloé y Aysén. Los autores advertían que esta expansión tenía caracteres graves debido a la alta tasa de nacimientos de esta especie de elevado potencial biótico, con lo cual las zonas invadidas debían soportar una fuerte sobrepoblación animal, con graves consecuencias para la ganadería y agricultura. El fenómeno de la plaga de conejos en Chile había sido particu-

105 E. Bellido, "Plagas devoran Juan Fernández. Animales y vegetales exóticos amenazan equilibrio ecológico del archipiélago", en La Nación, Santiago, 4 de junio de 2004.

106 "Controlarán especies dañinas de archipiélago Juan Fernández", en La Tercera, Santiago, 8 de julio del 2005. En sección noticias de web CONAF.

107 "Inician estudio para salvar biodiversidad del archipiélago de Juan Fernández", en La Nación, Santiago, 23 de octubre de 2005. 
larmente notorio en las provincias de Magallanes y Malleco, ocasionando incluso un aumento de la erosión ${ }^{108}$.

En este contexto, la industria forestal también se vio complicada por la presencia del conejo. Específicamente por los hábitos alimentarios de esta especie, que acostumbra comer el ápice de crecimiento de los pinos insignes, lo cual impedía el desarrollo vertical del árbol y producía un crecimiento achaparrado, producto del rebrote de yemas laterales. El conejo podía llegar a dañar hasta el 100\% de las plantaciones, y el replante, además del costo de reinvertir en plantar, significaba la pérdida de la bonificación estatal y el retraso en un año en la explotación final del rodal afectado ${ }^{109}$. En este sentido, Jaksic y Fuentes señalaban que "los conejos son temibles en las plantaciones forestales, y sus efectos negativos sobre los almácigos de pinos son sobradamente conocidos"110.

CONAF publicó, en 1974, el boletín "El conejo silvestre en Chile", donde planteó que el

“enorme daño que ocasiona el conejo silvestre en la reforestación, ha sido una de las causas principales de dedicar recursos y esfuerzos por parte de la Corporación Nacional Forestal para estudiar y aplicar técnicas avanzadas de control racional de este animal [...] al cabo de cincuenta o más años el conejo silvestre está ocupando prácticamente todos los ambientes donde de una forma $u$ otra le ha sido posible llegar y aclimatarse, a excepción de algunas regiones altoandinas, área norte de la provincia de Magallanes y provincia de Aysén"111.

De acuerdo con los antecedentes que disponían, señalaban que el conejo silvestre alcanzaba su mayor importancia entre las provincias de Los Andes, por el norte, y Malleco, por el sur, y suponían que "la especie tiene como límite norte de distribución el valle del Limarí. Se ignora si este ha constituido una limitante ecológica o meramente física". A juicio de los autores del estudio, el método más adecuado de erradicación en Chile continental consistía en la aplicación de monofluoracetato de sodio 1.080, "a pesar de su alta peligrosidad para el hombre y los animales domésticos" 112 .

En este marco, en febrero de 1977, la revista El Celarauco, de la empresa de Celulosa Arauco, señalaba que "uno de los enemigos más implacables es el temido conejo silvestre, capaz de destruir hasta el $100 \%$ de una plantación de pino insigne". Más adelante indicaba que "se calcula que la población estable sube de los cinco millones y que, en determinadas épocas del año sobrepasa los treinta millones de ejemplares [...] en las zonas afectadas puede haber entre 4 a 15 conejos por

108 Jaime Péafur et al., "Estudio preliminar de mamíferos silvestres chilenos: su distribución, valor económico e importancia zoonótica", en Revista de la Sociedad de Medicina Veterinaria de Chile, Vol. 18, Santiago, enero-diciembre 1968, 6.

109 Jaime Rodríguez, "Alternativas de control de lagomorfos en plantaciones forestales", en Ciencia e Investigación Forestal, $\mathrm{N}^{\circ} 4$, agosto de 1988.

110 Jaksic y Fuentes, op . cit., 94.

111 CONAF, "El conejo silvestre en Chile", op. cit., 1.

112 Ibid., 3 . 
hectárea"113. Para controlar los conejos se utilizaba el compuesto 1.080, que es un poderoso tóxico que podía exterminar al $90 \%$ de los conejos, pero que, al mismo tiempo, con una baja concentración podía matar a un hombre. El tratamiento masivo contra los conejos se había iniciado por CONAF a principios de la década de los sesenta. En 1975 este servicio pasó "a manos de empresas privadas organizadas ese mismo año. Actualmente existen dos: TECFA Ltda. (sociedad del manejo técnico de la fauna) y EXCO (explotadora de conejos) que durante la temporada pasada trataron treinta mil hectáreas"114.

Estos riesgos debió considerar la resolución del Servicio Agrícola Ganadero del 25 de noviembre de 1982, que prohibió la importación, fabricación y uso del monofluoracetato de Sodio 1.080, considerando que era "un plaguicida altamente tóxico para el hombre" y que permanecía "en el organismo de los animales que lo han ingerido sin disminuir su toxicidad por lo que puede provocar el envenenamiento tanto de personas como de animales útiles, revistiendo esta situación especialmente gravedad por no existir antídotos para el tratamiento de los intoxicados"115. En este diagnóstico concordaban Cruz y Rivera, del Grupo de Investigaciones Agrarias, quienes señalaban que "los pesticidas de alto contenido tóxico que se usaban para eliminar los conejos silvestres, también afectaban a los campesinos, sus animales domésticos y animales de caza"116. Para Aarón Caviedes y Antonio Lara, la aplicación de venenos para matar conejos era otro de los impactos ambientales negativos de las plantaciones forestales, pues ello significaba también la muerte de aves y mamíferos silvestres. A este impacto se sumaba el ecológico, pues los venenos provocaban una fuerte disminución de la fauna, en especial de los carnívoros, encargados de regular las poblaciones de herbívoros, lo cual producía "una alteración del equilibrio natural que facilitaba el aumento de los conejos"117.

Pese a las advertencias del daño ambiental ocasionado por el uso de este veneno, Jaime Rodríguez, profesor de Ecología y Fauna Silvestre de la Universidad de Chile, precisaba que, años después de la resolución del Servicio Agrícola Ganadero, el compuesto 1.080 seguía utilizándose, ya que "debido a la falta de productos sustitutos en el mercado, dicha resolución se prorrogó por un año. Esto ha sucedido cada año hasta el presente (1988)" "118. Como alternativa de control del conejo, Rodríguez rechazaba la introducción del virus mixoma, por el riesgo grave de contagiar a los conejos de criaderos, y también los métodos de captura y depreda-

113 "Se le acabó la suerte al conejo: Se le acusa de destructor de plantas de pino", en El Celarauco, Año IV, $\mathrm{N}^{\circ} 29$, Arauco, febrero de 1977, 8.

114 Idem.

115 Servicio Agrícola Ganadero, "Prohíbe la importación, fabricación y uso del Monofluoracetato de Sodio 1.080", Santiago, 25 de noviembre de 1982.

116 María Elena Cruz y Rigoberto Rivera, Cambios ecológicos y de poblamiento en el sector forestal chileno, Santiago, GIA, 1983.

117 Aarón Caviedes y Antonio Lara, La destrucción de bosque nativo para ser reemplazado por plantaciones de pino insigne: evaluación y proposiciones, Santiago, CODEFF, 1983.

118 J. Rodríguez, "Alternativas de control de lagomorfos en plantaciones forestales", en Ciencia e Investigación Forestal, $\mathrm{N}^{\circ}$ 4, Santiago, agosto de 1988. 
ción, ya que habían demostrado ser ineficaces en Chile. Respecto de los métodos químicos, señalaba que diversos ensayos de control de lagomorfos en plantaciones forestales, con anticoagulantes de segunda generación, habían entregado muy buenos resultados, siendo incluso mejores que los obtenidos por el monofluoracetato de sodio 1.080. Según sus pruebas, recomendaba la utilización de bloques parafinados de brodifacoum, conocido también como klerat, ya que tenía buena aceptación entre los lepóridos, ejerciendo un eficaz control contra el daño y disminuyendo el riesgo, tanto para hombres como para animales beneficiosos, ya que posee antídoto y su dosis letal es elevada ${ }^{119}$.

El año 2002, Ovalle, Ojeda y Skewes señalaban que el tagasaste (Chamaecytisus proliferus palmensis) fue introducido en Chile, el año 1988, por el Instituto de Investigaciones Agropecuarias (INIA), como parte de un proyecto de búsqueda y selección de arbustos y árboles forrajeros que contribuyesen al mejoramiento de la producción ganadera en las zonas de secano. Sin embargo "una de las limitantes de mayor importancia en el establecimiento del tagasaste es el daño provocado por lagomorfos (conejos y liebres), en el período comprendido entre la plantación y el primer año de vida de la planta"120. Lo cual nos indica que en el siglo XXI el conejo sigue siendo una plaga en Chile central, en tanto problema para la silvicultura y el hombre, y que las dificultades para controlar su excesivo crecimiento poblacional persisten.

\section{CONCLUSIONES}

El conejo europeo fue introducido en Chile en una fecha incierta. Las primeras referencias sobre la existencia de conejos en el país son de mediados del siglo XVIII y fueron realizadas por el abate Molina, para describir a los europeos ciertas especies chilenas como los cuyes y las vizcachas. En el siglo XIX, varios autores se refieren a la existencia de conejos y conejares en Chile central. Algunos aconsejan la crianza de este animal por sus beneficios económicos, mientras que otros advierten sobre los peligros que para la agricultura podía significar la aclimatación de esta especie. No es posible establecer si el asilvestramiento del conejo fue intencional o casual. ¿Se escaparon los conejos de los planteles de cunicultura? o bien ¿fueron liberados a los campos en forma intencional para practicar la caza y obtener carne y pieles? Las fuentes manuscritas no han dejado huella sobre estas interrogantes.

Lo cierto es que, a principios del siglo XX, muchos observadores comenzaron a advertir de los peligros que entrañaba el "conejo en libertad". Es posible presumir que muchos conejares no habían sido construidos bajo estrictas normas de seguridad, y que ello se comenzó a notar especialmente en la segunda mitad de la

\footnotetext{
119 Idem.

120 C. Ovalle, F. Ojeda y O. Skewes, "Evaluación de distintos métodos de prevención de daño causado por lagomorfos en plantaciones de tagasaste (Chamaecytisus proliferus ssp. palmensis)", en Agricultura Técnica, Vol. 62, Nº 3, Santiago, julio 2002, 396.
} 
década de 1920. Desde entonces, la presencia del conejo como plaga es descrita, a veces con dramatismo, en Chile central, Tierra del Fuego y el archipiélago Juan Fernández. Frente a esta realidad, el Estado respondió formulando políticas públicas que han intentando detener la plaga de conejos. En la década de 1930, se vedó la caza de los zorros, lo cual permitió la protección de estas especies y la desarticulación de buena parte de la industria peletera nacional. No obstante, tal como se comprobó décadas después, los zorros chilenos se alimentan solo marginalmente de conejos, pues se encuentran mejor adaptados para depredar otros animales nativos, lo cual nos indica que esta política fue fundada sobre bases erradas y que no debió tener resultados. Posteriormente, la industria forestal debió recurrir a un potente y peligroso veneno, que no tiene antídoto en caso de envenenamiento humano. Persisten, entonces, las dificultades para controlar esta especie invasora en Chile central.

En la actualidad, existen evidencias de que el problema del "conejo en libertad" en Chile central no ha sido resuelto en forma definitiva. En el caso de Tierra del Fuego, después de una alarma generalizada que incluyó la llegada a la zona de cazadores, trampas, venenos y depredadores, el Estado implementó exitosamente la introducción del virus mixoma, entonces ampliamente reconocido en el ámbito mundial por su eficacia para controlar el crecimiento desmedido de las poblaciones de conejos. En el archipiélago de Juan Fernández, tras años de financiamiento internacional y esfuerzos nacionales, los conejos siguen siendo una especie difícil de controlar. 